\title{
CONDITIONING IN PSYCHOTICS
}

David A. Chambers

Thesis submitted to the

Faculty of Graduate Studies and Research

in partial fulfillment of the requirements

for the

Degree of Doctor of Philosophy

\author{
McGil] University \\ Montreal \\ January, 1962
}




\section{ACKNOWLEDGMENTS}

The author wishes to acknowledge his indebtedness to Dr. C.A. Roberts, Medical Superintendent; Dr. H.E. Iehmann, Clinical Director; and Drs. C.H. Cahn and K. Ferguson, Verdun Protestant Hospital, Verdun, Quebec, for their support and assistance in selecting subjects for the first study. Recognition is also given to the National Employment Service, Lachine, Quebec, who supplied volunteer Ss. The first study was supported by Grant No. 604-5-57 from the Department of National Health and Welfare, Ottawa, to Dr. E.G. Poser, Verdun Protestant Hospital.

Acknowledgment is gratefully made to Dr. R.R. Gregory, Superintendent; Dr. W.W. Black, Clinical Director; and Drs. H. Vihvelin and A. Whiteside, Provincial Hospital, Iancaster, New Brunswick, for their support and assistance in selecting subjects for the second study; the Commissioner of Penitentiaries, Ottawa, and D.M. McLean, Warden, Dorchester Penitentiary, for permission to test inmates. Appreciation is also expressed to S.F. Hattie, R.N., for screening the inmate volunteers and to the prison staff generally for their cooperation.

The author wishes also to acknowledge his indebtedness to: the New Brunswick Telephone Company for their generous donation of electronic parts; A. Rungas for his technical skill in constructing several pieces of testing equipment; Dr. R.B. Malmo for his generous loan of a GSR amplifier; Areta Crowell, Patricia Richardson and J. Forde, graduate students at McGill University, for screening a list of verbs; and Drs. G.A. Ferguson and R.C. Gardner for statistical advice and guidance. 


\section{TABLE OF CONTENTS}

Page

Statement of Purpose

Historical Introduction _. . . . . . -

Statement of Problem - $\ldots \ldots-\ldots$

Study I

Method

Results

Study II

Method

Results

Discussion

Surmary

Appendices

References
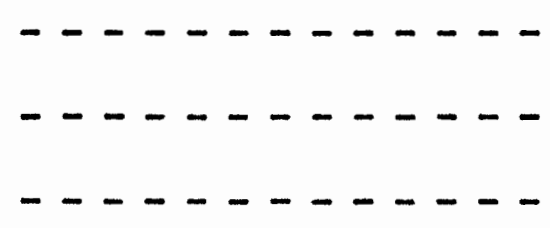

30

42
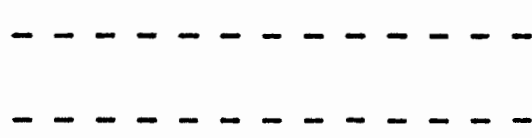

42

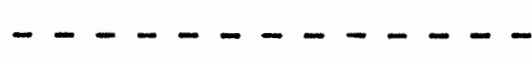

44

60
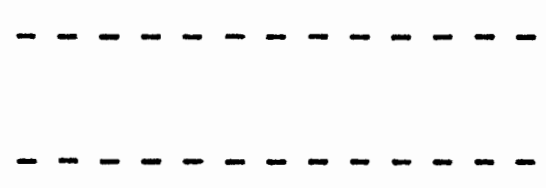

69

70

77 
STATEMENT OF PURPOSE

The term 'psychosis' is widely used in descriptive psychopathology but is usually non-specific regarding symptoms. Although 'psychosis' is a generalization which cannot be defined (Diethelm, 1953, p. 25), it is generally understood to denote disordered behaviour characterized by "... personality disintegration and failure to test and evaluate correctly external reality in various spheres. In addition, individuals with such disorders fail in their ability to relate ... to other people or to their own work" (American Psychiatric Association, Committee on Nomenclature and Statistics, 1952, p. 24; Dominion Bureau of Statistics, Health and Welfare Division, 1954, p. 34). While it is not possible under the present state of knowledge to define the concept further, it is the intent of this research to base an experimental inquiry upon what is known about the condition.

Two characteristics seem to be required before behaviour is termed 'psychotic': the behaviour must be considered highly undesirable by society, and these behavioural acts must be judged to have a high probability of recurrence. If these two aspects - deviant response acts and frequency of occurrence - are important parameters of psychotic behaviour, then learning theory becomes a relevant line of inquiry.

Using a learning theory approach, the problem may be stated in terms of response acquisition and response retention. While pertinent information regarding the significant stimulus-response 
features of individual psychotic disorders is generally not known, an important contribution by Pavlov (1903) bears upon it. Pavlov suggested that psychopathology reflected a disturbance in either response acquisition or in response extinction. His formulation placed equal emphasis upon both aspects (acquisition and extinction) and he maintained that disruption of either function would lead to chaotic performance. The advantages of this formulation are obvious: firstly, it is concerned with observable behaviour and, secondly, it in no way delimits or rejects biological causal factors. Its major interest, however, lies in its emphasis upon learning.

Although numerous investigators have studied the conditioning performance of psychotics, they have employed only single conditioning techniques. In addition, they have for the most part overlooked other variables associated with psychotic illness, such as in-patient or out-patient status and socio-economic level, and they have seldom provided cross-validation of their findings. Consequently the information given is limited and in some cases its comparative use has been further restricted by an uncritical choice of experimental and/ or control subjects (ㅇs). The employment of several conditioning techniques, together with control for institutionalization and socioeconomic level and provision for cross-validation, would seem to be desirable in order to assess the validity of Pavlov's theoretical position.

The purpose of this thesis is to evaluate the conditioning performance of psychotic Ss relative to non-psychotics on each of three conditioning techniques. It is hoped that a systematic study of this 
nature will yield information helpful in evaluating the importance of the conditioning paradigm to an understanding of psychotic illness. 
HISTORICAL INTRODUCTION

The literature relevant to this thesis will be discussed under four sections: 1) autonomic conditioning, 2) skeletal conditioning, 3) free operant conditioning, and 4) verbal conditioning. Although many of the studies to be reviewed have been concerned with clinical or applied problems regarding psychosis, their research design, as pointed out by Franks (1961, p. 481), has often been inadequate. Therefore, each study is given in sufficient detail to indicate the degree of caution which must be exercised in generalizing from its results.

Autonomic Conditioning

Mays (1934) employed a discrimination design to study galvanic skin response (GSR) perseveration in 16 normals and 20 male catatonic patients. He reported that the conditioning performance of the patient group, in terms of resistance to extinction, was superior to that of the normals. This finding was interpreted as giving support to the clinical observation that response repetition or perseveration is one of the primary characteristics of catatonics. Shipley (1934), also using a discrimination design, extended this interpretation to other sub-categories of schizophrenics. He investigated GSR conditioning in six graduate students, 17 schizophrenics (excluding catatonics), 10 manic depressives and nine mixed neurotics. Shipley theorized that perseveration was simply a set to act in a certain way and thus could be understood in terms of a lowered response threshold to stimuli. His experimental situation 
provided four criteria with which to assess excitatory tendencies: 1) resistance to adaptation, 2) conditionability, 3) experimental extinction, and 4) irradiation. A combined score for the four criteria showed the schizophrenics to be most perseverative, with the manic-depressives, neurotics and normals following in that order. The schizophrenics evidenced more rapid response acquisition than the other three groups. In contrast to Mays' study, however, the schizophrenics were not more resistant to extinction. This finding is of marked interest because, although the two studies utilized different aversive stimuli, they followed similar discrimination designs. Both authors reported greater perseveration for schizophrenics than for normals, Mays on the basis of extinction data and Shipley on the basis of a combined score. Although it is not possible to reconstmuct the data so as to apply significance tests, it is doubtful whether a more thorough statistical analysis would modify these conclusions.

Shipley suggested that the difference between his results and those of Mays regarding resistance to extinction might have been due to differences in the diagnostic categories studied. While logical, this explanation would require that the reliability of diagnosis of sub-categories be reasonably high, an assumption which many studies have questioned (Ash, 1949; Doering, 1934; Hunt, Wittson and Hunt,

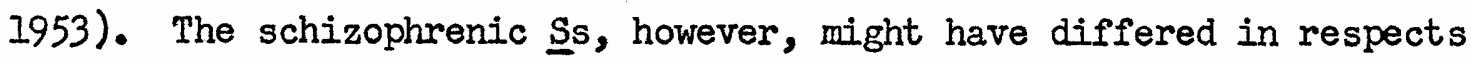
other than catatonia, for instance, treatment history or length of illness.

Attempts to study the effect of therapeutic intervention in GSR 
conditioning rates have been made by Peters and Murphree (1954) and Brown (1957). Unfortunately, the data of both these studies are inconclusive and do not provide adequate support for the positive results reported.

The possible importance of chronicity or length of illness has been indicated by Howe (1958). Employing a classical conditioning design, Howe investigated GSR extinction rates in 60 normals, 60 anxiety in-patients, and 96 chronic schizophrenics (36 of whom were found to be unconditionable). Each $\underline{S}$ was given eight acquisition trials (tone and shock) followed by eight extinction trials. Using magnitude of response through extinction, he reported stronger conditioning in the anxiety states than in the other two groups. The normals and testable schizophrenics were found not to differ, thus lending support to Shipley's study.

The 36 unconditionable schizophrenics had been given a stronger unconditioned stimulus (UCS) $\left(p_{<} .05\right)$ and had been ill longer $(p<.01)$. Howe concluded on the basis of this information that predictions concerning autonomic conditionability of schizophrenic Ss should take into account the degree of chronicity and possibly the amount of deterioration present. This conclusion, however, may require modification following an investigation by Stewart, Winokur, Stern, Guse and Pfeiffer (1959). These authors also investigated GSR conditioning with tone as the conditioned stimulus (CS) and shock as the UCS. They studied 70 psychiatric patients selected from five active treatment units. Their four groups, which appear to have been acute cases, comprised 28 manic depressives, depressed; 
18 schizophrenics; 15 personality disorders; and 10 anxiety states. Each $\underline{\text { S }}$ was given 11 acquisition trials followed by 15 extinction trials.

The authors reported that the personality disorder group had a significantly faster acquisition rate than did the two psychotic groups and that the anxiety group tended to condition more quickly than the schizophrenics. Significantly more responses were given during the extinction trials by the personality disorder and anxiety groups than by the psychotics. None of the differences between the two psychotic groups was significant.

These findings not only support Shipley and Howe but extend their results to manic depressive patients as well. The similarity of the extinction data between Howe's study and that of Stewart et al. suggests that chronicity may not be a crucial variable. Howe indicated chronicity on the basis of the psychotic patients whom he was unable to condition. It is possible, however, that severity of illness rather than years of illness was the important factor. Stewart et al. also stated that a number of schizophrenic Ss could not be considered for conditioning or were unable to complete the procedure but further information covering this group is not given. Severity of illness could account for Howe's data on the unconditionable patients and seems an adequate explanation also for the experience reported by Stewart et al. Chronicity and deterioration, on the other hand, appear to be less parsimonious explanations. Skeletal Conditioning

Many studies have shown that skeletal conditioning may be ob- 
tained in psychotic Ss. Grecker (cited by Razran, 1934) studied a tactile response in four normals and two catatonics. He reported that the two groups were similar both in speed of acquisition and in stability of the response. This finding has been supported by Pfaffman and Schlosberg (1936) who studied the formation of the conditioned knee jerk in 19 manic depressives, 25 schizophrenics and 20 undergraduate students. The performance level of the psychotic Ss, although slightly higher, was not significantly different from that of the normals.

Bender and Schilder (1930) used handwithdrawal conditioning to study response to pain in 16 schizophrenic patients. They reported that, while conditioned reactions were established, ease of acquisition appeared dependent upon the patient's level of attention. Mirolgrubou and Ugol (1933), Guk (1934) and Landkof (1938) have also reported difficulty in obtaining avoidance conditioning in small groups of schizophrenics. The difficulty experienced by these authors may have been a function of the response system studied rather than particular to the reinforcement used. Ivanov-Smolensky (1925) reported that a non-avoidance response (motor component of the food reflex) was both difficult to establish and unstable in seven manic depressives.

Gantt (1952), in a review of his own work, provides clinical information which suggests that the psychogenic psychotic acquires a motor response about as well as do normals. On the basis of a similar technique, Fleck (1953, p. 369) states that "... schizophrenics and compulsive patients show conditioned reactions ... more often and 
more definitely than better adjusted individuals ...." Gantt's general finding that organic or toxic impairment greatly limits or abolishes the ability to form conditioned responses supports the earlier observation of severe impairment in the conditioning ability of seniles reported by Tatarenko (1934).

The observation that organic impairment can lead to permanent abolition of the ability to form conditioned motor responses is important. Organics may not be singular in this respect, however, The work of Astrup (1957) with psychotics has presented evidence that severity of illness is also a variable which must be taken into account. Using handwithdrawal to shock, Astrup investigated 122 chronic schizophrenics. He reported that acquisition performance seemed to be linear with severity of illness, ranging from near normal in the less ill to near absence in the severely ill. Data on eyeblink conditioning, using psychotic $\underline{S} s$, have been reported in three papers. Spence and Taylor (1953) investigated 21 psychotics, 34 neurotics and 45 normals. The patients were obtained from the in-patient and out-patient services of a psychiatric institute. The psychiatrist in charge of each case referred only those patients who, he felt, would cooperate and who would not suffer from the experience in such a way as to retard therapy.

Each S received 80 acquisition trials and 10 extinction trials, although extinction data are not reported. Using stringent latency criteria, the authors reported that the psychotics conditioned better $(p<.05)$ than the normals or the neurotics and that no significant difference was found between the latter two groups. 
Taylor Manifest Anxiety Test scores were available for all Ss except two normals. Analysis of these data with the normal group revealed a significant relationship with conditioning performance, high scores being associated with superior conditioning. The productmoment correlation between the two variables was 0.25 which, while significant with a one-tailed test, indicated that the variance comunality was small. A comparable examination of the patients anxiety scores was not attempted because of their markedly constricted range.

In an extension of this study (Taylor and spence, 1954) the authors increased the neurotic group to 74 and the psychotic group to 42 and discarded the normal group. They reported that the performance of the psychotics was still superior to that of the neurotic group but only between the .05 and .10 confidence levels. Thus the positive finding of the first study, that psychotics acquire the conditioned eyeblink more rapidly than neurotics, was questioned. The inability to substantiate their earlier results is provocative, especially when it is noted that the first study contributed nearly half the data of the second report. It is possible that the in-patient - out-patient

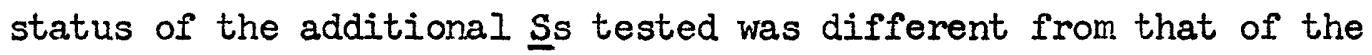
initial group. Unfortunately no comparisons between these subsamples or between the patients of the first study and the patients added for the second study were given. The possibility that the two groups of patients may have differed and that this difference may have been related to the adequacy of their functioning, i.e. out-patient vs. in-patient, is strengthened by the work of O'Connor and Rawnsley (1959). 
These authors studied eyeblink conditioning in 20 normals, 20 chronic non-paranoid and 20 chronic paranoid schizophrenics. They reported that although the extinction levels of the normals and non-paranoid patients did not differ, the normals were significantly $(p<.05)$ more resistant to extinction than were the paranoid patients. Operant Conditioning

The application of 'free-operant' conditioning methods to the study of psychotic behaviour has been the subject of several research reports (Iindsley, 1956a, 1956b, 1960; Iindsley and Skinner, 1954; Skinner, 1954, 1956; Skinner, Solomon and Lindsley, 1956). Although these reports are concerned mainly with methodological problems, they do present some data regarding operant behaviour of psychotics together with provisional statements regarding the performance of psychotics relative to non-psychotics.

Iindsley and Skinner (1954) studied 15 chronic male psychotic patients. Each patient was conditioned to pull levers, under reinforcement of candy, cigarettes or pictures, for one hour per day for 70 hours. The authors reported that the behaviour of the psychotics was responsive to reinforcement and that while marked individual differences were observed stable response rates were developed. In a Iater study (Skinner et al., 1956), 23 chronic psychotics were found to have response rates significantly lower than those of 18 attendants. The performance of the patients under non-reinforcement was, however, significantly more resistant to extinction.

A performance differential between normals and chronic psychotics during response acquisition has also been reported by Mednick and 
Lindsley (1958), who investigated 12 untestable chronic psychotics (unable to free associate to the Rorschach), 10 testable chronics and six attendants. The response rates of the normals were significantly higher than those of the patients and the response output of the testable chronics was significantly higher than that of the untestable group.

The Iower operant emission behaviour of the chronic psychotics has been reported (Iindsley, 1956b, p. 152) to correlate significantIy $(p<.01)$ with severity of ward behaviour when using the I-M FergusFalls scale (Iucero and Meyer, 1951). King, Merrell, Iovinger and Denny (1957) attempted to verify this relationship with acute psychotics. They studied 30 recently admitted schizophrenics who had been referred for coma insulin therapy, and observed a curvilinear relationship between severity of illness and rate of operant responding, the group evidencing medium severity of illness responding at the highest operant rate. The index of severity in this study was the mean of three judges' ratings and thus the co-variance examination may have been based on different information than would have been supplied by the Fergus-Falls scale. It is also possible that the rating/operant interval may have varied between groups. The importance of this factor has been indicated recentIy by Mednick and Iindsley (1958) who have show that correlations between ward behaviour ratings and operant response levels are functionally related to the time intervals existing between the two measures. Correlations reported by these authors were significantly different from zero only when based on response data intimately related to the date of the clinical rating.

The suggestion of a Iinear relationship between these two variables 
(severity of behaviour disorder and operant rate) with chronic psychotics has been confirmed by King, Armitage and Tilton (1960). They reported a significant rank-order correlation $(p<.05)$ between severity of illness (based on a composite rating scale) and operant response rates of 12 chronic schizophrenics.

\section{Verbal Conditioning}

The literature covering verbal conditioning is extensive (Krasner, 1958a; Salzinger, 1959) but has reference for the most part to the performance of non-psychotics. Nevertheless, a number of studies have established that, while the verbal behaviour of psychotics can be manipulated, there are important differential reinforcement parameters associated with these $\underline{\text { Ss. }}$

Taffel (1955), in a study important for its methodology, investigated the relationship between verbal conditioning and manifest anxiety in 90 recently admitted psychiatric patients. These $\underline{\text { ss were }}$ divided, on the basis of their scores on the Taylor Manifest Anxiety Scale, into three groups each of which contained 10 low, 10 medium and 10 high anxiety patients. Group I received the verbal reinforcement "Good" to I and wE sentences; Group II received a light, and Group III served as a control group. Significant acquisition was reported only for the medium and high anxiety patients receiving the verbal reinforcement "Good".

Two studies (Buss and Gerjuoy, 1958; Levin, 196I) have failed to confirm Taffel's finding that verbal acquisition was contingent upon anxiety level. Buss and Gerjuoy (1958) studied 45 Ss (2l male and 24 female) described only as State Hospital psychiatric patients. In 
contrast to Taffel's results, they reported that high anxious $\underline{S}$ failed to show conditioning whereas significant response acquisition was obtained with low anxious patients. Ievin (196I) studied verbal conditioning, using the card technique, in 79 patients described grossly as 29 medical patients and 50 neuropsychiatric Ss. He reported that anxiety level as measured by the Taylor scale was unrelated to conditioning performance.

The uncritical use of psychiatric patients by Taffel (1955), Buss and Gerjuoy (1958) and Ievin (196I) seriously restrict the generality of their findings. The importance of providing information regarding patient variables has been indicated in a study by O'Connor and Rawnsley (1959). These authors employed a verbal conditioning procedure evolved by Luria (1956), which required the $\underline{\mathrm{S}}$ to develop a lever press response to a light and then to generalize this response to the word "Iight". They studied 20 male nurses, and 20 chronic paranoid and 20 chronic non-paranoid schizophrenics. The normals and non-paranoid patients were found not to differ on response acquisition but both groups were significantly superior to the paranoid schizophrenics. In a complex study using Taffel's sentence construction technique, Hartman (1955) investigated verbal conditioning in 84 male attendants and 84 male patients. The patients were resident in a veterans administration hospital with a diagnosis of schizophrenic reaction. Hartman used 160 stimulus cards, each card having a verb in the past tense and four personal pronouns ( $I, W E, H E, T H E Y$ ) on it. Four treatment groups were formed, each composed of 21 attendants and 21 patients. Group I received the verbal reinforcement "Good" on completion of I and 
WE sentences; Group II received the gestural reinforcement of a "nod" on the completion of I and WE sentences; Group III received the gestural negative reinforcement of a head "shake" on the completion of HE and THEY sentences; and Group IV served as a control group. The first 20 trials were the same for all Ss and indicated their operant level; trials 2I-80 were acquisition and trials 8I-160 were extinction trials.

Hartman (1955, pp. 31-32) reported that no generalized conclusions could be drawn from the data concerning the relative effectiveness of the three reinforcers, and that there was no adequate support for the hypothesized response differential between schizophrenics and normals to social rewards and punishments. His final statement, although lacking supporting data, was to the effect that the presence of strong competing habit structures may impede manipulation of schizophrenic verbal behaviour.

The factor of habit competition has been investigated in two complementary studies (Cohen, Kalish, Thurstone and Cohen, 1954; Cohen and Cohen, 1960). In the first study (Cohen et al., 1954) the authors reported two experiments. Experiment I demonstrated significant verbal response acquisition in 20 male ambulatory patients under the reinforcement "Good" to I and WE sentences, and no change in a control group. In experiment II, 75 medical patients were studied. Each $\underline{\mathrm{S}}$ was reinforced with the word "Good" whenever he selected I or IE pronouns during the first 80 trials. For the second 80 trials the $\underline{S}$ were randomly assigned to one of three groups: Group I received no further reinforcement, Group II received reinforcement to competing responses $\mathrm{HE}$ 
and THEY, and Group III continued to receive reinforcement of $I$ and $W E$. Extinction effects were reported only for Group II members, together with a significant increase in their use of HE and THEY responses, and demonstrated that competing responses could be modified.

The second study (Cohen and Cohen, 1960) investigated verbal conditioning in 16 schizophrenics and 16 neurotics. Significant acquisition was reported for the neurotics but no effect was shown for the schizophrenic Ss. The authors suggested that saying "Good" to this latter group was functionally equivalent to saying nothing to nonschizophrenic Ss.

The reliability of the reinforcing properties of "Good" when used with psychotic $\underline{S}$ sould thus appear to be of a low order. Hartman (1955) reported that "Good" was effective only when used in conjunction with a strong response preference. Cohen et al. (1954) reported that "Good" was effective, regardless of pronoun preference, with normals, whereas Cohen and Cohen (1960) found that it was ineffective with schizophrenics. However, other reports (Taffel, 1955; Buss and Gerjuoy, 1958) have indicated that the use of "Good" elicited reliable modifications in the verbal behaviour of psychiatric patients (neurotics and psychotics).

A study by Ieventhal (1959) bears directly upon this problem of diagnosis. Using the stimulus card procedure, Leventhal studied 180 Ss: 60 schizophrenics, 60 neurotics and 60 ambulatory medical patients. All Ss were male first admissions and had been hospitalized for less than four months. Four treatment groups were used, each containing 15 Ss from each diagnostic category. Group I (reward) received "Good" 
following the use of the selected pronouns; Group II (punishment) received "Not so good" following the use of alternative pronouns; Group III (reward-punishment) received "Good" following the use of the selected pronouns and "Not so good" following the use of the alternative ones; Group IV served as a control group. The normals evidenced significant and equal learning under all three treatment conditions. The neurotics failed to acquire the response bias under treatment II (punishment) condition and the schizophrenics evidenced acquisition failure under treatment I (reward) condition. Thus Leventhal's data indicated that verbal reinforcers might possess differential efficacies dependent upon certain population characteristics.

The effect of social reinforcements other than "Good" upon the verbal behaviour of schizophrenics has been studied by several authors (Salzinger and Pisoni, 1958, 1960; Krasner, 1958b; Krasner and Ullmann, 1958; UlImann, Krasner and Collins, 1961). Manipulation of 'affect' responses during the clinical interview was investigated by Salzinger and Pisoni (1958) with 36 schizophrenics and later (1960) with 26 general medical patients. Affect statements were reinforced with phrases such as "Mimm", Uhuh", "I see", and other common positive interjections. The authors reported that reliable conditioning under these reinforcers occurred in both groups, with the schizophrenics evidencing more rapid extinction.

Sinilar results based on a story-telling technique have been reported by: Krasner (1958b) with two male patients diagnosed as schizophrenic reactions in remission; Krasner and Ullmann (1958) with 15 
hospitalized male schizophrenics; and by Ullmann et al. (1961) with 30 psychotics. Although these three studies presented clear evidence of the modifiability of verbal behaviour of patients, they gave no information regarding normals. Thus it is not possible to assess the performance of patients relative to non-psychotics. Summary and Discussion of the Iiterature

The studies reviewed demonstrate that the behaviour of psychotic Ss may be modified through conditioning procedures. The autonomic, skeletal and operant conditioning data indicate that severity of psychotic illness and possibly chronicity and deterioration may lower responsivity and retard acquisition rates. The operant conditioning studies further suggest that there may be valid differences between the response rates of acute and chronic patients. The verbal conditioning data, although not directly concerned with differential performance of psychotic sub-groups, has drawn attention to the possibility that the efficacy of a reinforcer may vary. In recognition of this problem, Skinner et al. (1956), for example, employed candy with psychotics and money with normals as reinforcement during operant conditioning.

Statements regarding the general ability of psychotics to acquire or to retain a conditioned response, however, cannot be made with any degree of confidence. The studies reported have with few exceptions employed different conditioning procedures and have investigated different response systems. While the assumption may be made (Eysenck, 1957; Foley, 1943; Murphy, 1947; Vogel, 1960) that the ease with which a $\underline{S}$ conditions in one situation is related to the ease with 
which he will condition in another, there is little evidence to support it. Using response latency, amplitude and frequency, Campbell (1938) found no relationship between two types of defensive skeletal conditioning (eyeblink and knee jerk). Small but significant positive correlations, however, have been reported (willett, cited by Jones, 1960) between measures based on salivary, spatial and verbal techniques. These correlations, being of the order of 0.20 , suggest that while a common factor may be present it would account for only a small proportion of the variance.

Precise comparisons between experiments require that the indices used be comparable. It has been pointed out (Osgood, 1953, p. 327) that different measures of habit strength (latency, amplitude, frequency) yield different interpretations. Hilgard and Marquis (1940, p. 119) have likewise show that the information provided by acquisition data may be different from that given by extinction data. Therefore the possibility of generalizing even on the basis of studies which have investigated similar response systems is limited.

Generalized statements regarding the conditioning ability of psychotics are further restricted by the absence of control groups. A number of investigations (Astrup, 1957; Bender and Schilder, 1930; Stewart et al., 1959; Taffel, 1955; Taylor and Spence, 1954) have been concerned only with patient groups. Several studies (Howe, 1958; Mays, 1934; Pfaffman and Schlosberg, 1936; Shipley, 1934; Spence and Taylor, 1953) have employed university students as control Ss, thus neglecting to take into account factors of socio-economic status. In this regard the work of Brooke (1959) and of Hollingshead and 
RedIich (1953) is of importance. These authors have reported that a disproportionate number of mental hospital patients are from the lower socio-economic strata. It might be argued, therefore, that control groups should reflect a similar bias. It should be pointed out also that the factor of institutionalization has received little attention. Although attempts (Leventhal, 1959; Salzinger and Pisoni, 1960) have been made to control for this factor through the use of ambulatory medical patients, it is doubtful that the environments of general hospitals and mental hospitals are comparable.

Inadequate description of patient populations restrict the interpretation of several studies. Astrup (1957) investigated 'deficit' schizophrenics; Buss and Gerjuoy (1958), Levin (196I) and Taffel (1955) studied combined psychotic and neurotic patients; Hartman (1955) stated schizophrenic reaction to be the diagnosis of the patients he studied; and Spence and Taylor (1953) and Taylor and Spence (1954) have indicated that the psychotics they investigated were in-patients and out-patients and that they were selected by the psychiatrist in charge as being cooperative.

Imperfections in psychiatric diagnostic classification are well known so that detailed information regarding basic parameters such as in-patient or out-patient status, certified or voluntary admission, acute or chronic condition, treatment or non-treatment regime, and the like is required before comparisons between studies may be made. 


\section{STATEMENT OF PROBIEM}

The research to be reported here is concerned with the systematic examiration of the conditioning ability of psychotics relative to nonpsychotics. Although numerous studies have compared the conditioning performance of psychotics and control Ss they have generally used single procedures and often have only investigated either acquisition or extinction effects. The present study, using three conditioning procedures and investigating acquisition and extinction performance on each, is an attempt to provide more systematic information with which to evaluate the conditioning ability of psychotics. Emphasis was

placed upon control of both $\underline{S}$ factors and measurement factors. The importance of such control has been succinctly stated by Bindra (1959) and the procedures adopted in this study have followed closely his


economic levels and attempts were made to provide control for institutionalization. Statistical control was attempted over such factors as severity and chronicity of illness. Partial crossvalidation was provided for through the inclusion of two separate groups of chronic psychotics and in order to broaden the basis for generalization the research was conducted in two different geographic areas. The hypothesis under test is that the conditioning performance of psychotic S Ss evidence acquisition or extinction effects that are different from those of non-psychotics. On the basis of the literature, two secondary hypotheses have been formulated. These are that severity of psychotic illness correlates with conditioning performance and that acute psychotics perform differently from chronic psychotics. 


\section{STUDY I}

Method

\section{$\underline{\text { Subjects }}$}

Two groups of male $\underline{S} s^{I}$ were tested. Group I consisted of 44 patients selected from the chronic wards of a large mental hospital. All met the following criteria: without signs of organic impairment, classified as chronic psychotic, continuous hospitalization for at least five years prior to testing, and no physical treatment for at least four months prior to testing. Fifteen $\underline{S}$ were not able to respond to the testing situation and were eliminated from the study. The diagnoses given in the medical records of the remaining 29 patients were: schizophrenia, 26; manic depressive, depressed, 3. The mean number of years in hospital for this group was 12.86 (S.D. $=7.75$ ). Prior to testing, each patient was withdrawn from all medication for a period of five days.

Group II consisted of 26 paid volunteers recruited by the National Employment Service from unskilled labourers who were receiving unemployment benefits. Two Ss were discarded, one because he had been under psychiatric care and one because he attended only the initial testing session. The socio-economic status of the remaining 24 Ss was similar to that of the Group I $\underline{S} s$, but unlike the Group I $\underline{S} s$ they were nonpsychotic. For the purpose of this research, therefore, Group II will be referred to as normal, even though it represented a marginal sample of the general population.

\footnotetext{
I Information regarding age and education is given in Table I.
} 


\section{Procedure and Apparatus}

All testing was carried out in a semi-sound-proofed room. Recording and control equipment were located in an adjoining room fitted with a one-way screen which allowed the experimenter to see into the testing room.

Following a short interview, each $\underline{\mathbf{S}}$ was given a brief descriptive statement regarding the research study and told that participation was

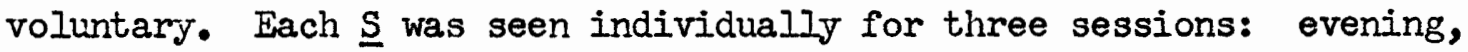
morning and afternoon. During session I a series of tests was administered to each $\underline{S}$. The abbreviated Wechsler Adult Intelligence Scale (WAIS) (Doppelt, 1956) was used to obtain an estimate of intellectual functioning and the Taylor Manifest Anxiety Scale (MAS) (Taylor, 1953) was employed to provide information regarding anxiety level. Additional tests known to differentiate between psychotic and non-psychotic groups (Eysenck, 1952b; King, 1954) were also administered. Selection of these tests depended upon three criteria: that they discriminate psychotics, permit objective scoring, and their administration time lie within practical limits. These tests served the additional purpose of providing time for $\underline{S}$ to adapt to the testing room prior to the commencement of the conditioning procedures (see Kamin, 1955).

The tests selected are described below in the order of administration:

1. Body Sway Test (BST) (HuIl, 1933). The apparatus was similar to that described by Edwards (1939). The test instructions, via a phonograph, were as described by Eysenck (1952b). Score: degree of sway induced by suggestion, either forward or backward (whichever was 
the greater), measured in $\frac{1}{4}$ in.

2. MAS (Taylor, 1953). Score: number of anxiety items checked.

3. The Three Circles Test (3C) (Eysenck, 1952b). S was given a pencil and a sheet of paper $8 \frac{1}{2} " \times 1 I^{\prime \prime}$ and was told to draw three circles. Score: number of sec. taken.

4. Verbal Fluency (VF) (Kanfer, 1956). $\underline{S}$ was told to say as many words as he could. Score: number of words spoken in $30 \mathrm{sec}$.

5. Leg Persistence (LP) (Eysenck, 1952b). S, seated in a chair, was requested to hold his foot over the seat of another chair for as long as possible. Score: time in sec. that $\underline{S}$ held his foot above the other chair.

6. WAIS (sub-tests: Arithmetic, Vocabulary, Block Design and Picture Arrangement) (Doppelt, 1956). The sub-test scores were prorated to estimate the full scale score.

7. Reaction Time (RT) (King, 1954). The apparatus used was similar to that described by Malmo and Crisp (1945) and employed a chronoscope graduated in hundredths of a sec., which was activated when the stimulus (Iight) was presented and was stopped the instant $\underline{S}$ lifted his finger from the correct microswitch. The provision of two lamps and two switches enabled either simple or disjunctive RT to be studied. The verbal signal "Ready" was either regular (two sec. before light presentation) or irregular (variable, one to five sec. before light presentation) (Tizard and Venables, 1956). Five test series, each followed by $30 \mathrm{sec}$. rest, were used:

a) Practice, 25 trials right index finger, 25 trials left index finger, 25 disjunctive (both fingers). Finger use, under random 
order, followed Mueller (1959).

b) Simple Regular Interval (SRI), 50 trials (25 right, 25 left).

c) Disjunctive Regular Interval (DRI), 50 trials.

d) Simple Irregular Interval (SII), 50 trials (25 right, 25 left).

e) Disjunctive Irregular Interval (DII), 50 trials.

Score: mean time in hundredths of a sec.

8. Tapping (TAP), (King, 1954). A 4" $\times$ 6" metal target, mounted on a wooden board and connected through a 6-volt battery to a counter and a stylus, was used. Each $\underline{S}$ was given a practice trial followed by three test trials. Score: mean number of taps in $15 \mathrm{sec}$.

Three conditioning procedures were selected: GSR, verbal and salivation.

GSR. The circuit used for recording DC skin resistance has been described by Stenett (1957). This technique employs a standard voltage comparator bridge with a constant current $( \pm 2 \%)$. Electrodes were prepared as described by Woodworth and Schlosberg (1955, p. 139). A Harvard inductorium, using eight volts DC, provided electric shock. Shock electrodes were made from .020 brass shim stock cut $\frac{1}{2} n \times \frac{3}{4} "$. The output of a Heath Kit audio generator, model AG-9A, was fed through an amplifier to a pair of high fidelity padded head phones. Control over tone and shock circuits was obtained through the use of electronic timers. Continuous recording was made of all events on a $\mathrm{C} . \mathrm{H}$. Stoelting polygraph.

Shock electrodes were taped $1 \frac{1}{2} "$ apart to the shin (medial and

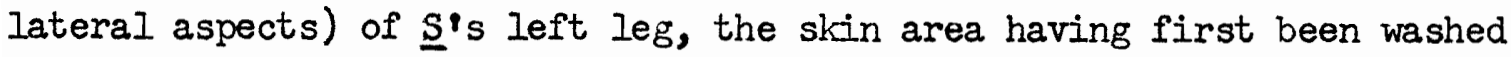
with alcohol and rubbed with electrode paste. The GSR electrodes were 
placed on the palmar and volar surfaces of the left arm. A $700 \mathrm{cps}$ tone of increasing amplitude was presented through padded high fidelity ear phones until $\underline{\mathrm{S}}$ stated that he could hear it clearly. After a fivemin. rest period a series of tones, lasting three sec., was given until the GSR was absent on three consecutive tones. A series of shocks of increasing intensity, lasting $50 \mathrm{~ms}$, was then given until three consecutive GSRs were recorded. The conditioning design followed the work of Bindra, Patterson and Strzelecki (1955) and Franks (1957). Each $\underline{S}$ was given 45 acquisition trials and 10 test trials ( 3 after each of the first 2 blocks of 15 acquisition trials and 4 after the last block of 15). Following a delay period of two min., 20 extinction trials were given. The CS (tone) lasted three sec. The UCS (shock) lasted $50 \mathrm{~ms}$ and co-terminated with the CS. The inter-trial interval was variable depending upon the time necessary for the $\underline{\text { ' }}$ 's resistance level to become stabilized. This interval was seldom less than 15 sec. or more than 45 sec. A conditioned response (CR) was scored on the 10 test trials and the 20 extinction trials if a resistance drop of 100 ohms or more occurred $1.7-4.7$ sec. following the onset of the CS. Verbal conditioning. The Thorndike-Iorge Word Book (1944, pp. 267270) was used for the selection of 180 verbs in the past tense. These were screened by three graduate students who deleted 54 verbs supposedly having emotional overtones (Richman, 1957). Each of the remaining 128 verbs (see Appendix A) was typed in capital letters in the centre of a 3" $x$ 5" white index card. After the cards were well mixed, eight of them were set aside. The five personal pronouns, I, $H E, S H E, W E$ and 
YOU, in counter-balanced order, were typed across the card in capital letters under the verb. The cards were then made into six decks of 20 under the provision that for every deck each pronoun appear in first position four times. Card position within each deck was randomly determined. A practice deck of five cards was made using verbs taken from the eight mentioned above. Cards 1 to 4 carried a verb and the first name MARY, JOHN, ALICE or TOM. Card 5 had a verb and all four names on it. The presentation apparatus consisted of a board having a $2^{\mathrm{n}} \times 3^{\prime \prime}$ aperture behind which the cards were hung one at a time during presentation. The panel was approximately 19" high and 24 " wide with the aperture about eye level for a seated $\underline{\text {. }}$ Ss were given the following instructions:

I am going to put cards here; they will have words on them. Your job is to make up a sentence with these words. For example, on this card there is the word IS and the word MARY. We could say Mary is a kind person'. 0.K. Now on this card there are the words THREW and JOHN. We could say 'John threw the ball'. On this card there are the words TIED and ALICE. Make up a sentence using these two words. 0.K. Now do the same for this card (SWAM and TOM). Now on this card there is the word SIEPT and under it four words, MARY JOHN ALICE TOM. Make up a sentence using one of the bottom words with the top word SIEPT. 0.K. Now on the cards that follow you will have one word on top and five words at the bottom, and you are to make 
up a sentence using it and any one of the words on the bottom; any sentence at all, but work quickly.

The 120 cards were presented one at a time. Responses to cards 1 - 20 provided a measure of the operant response level and received no reinforcement. Cards 21 - 80 were acquisition trials on which $\underline{S}$ was reinforced with "Good" whenever he completed a sentence using the pronouns SHE or $\mathrm{WE}$. Cards 81 - 120, extinction trials, were given without reinforcement. AII cards were presented in the same manner without pause or change in pattern.

Salivation Conditioning. The procedure followed was similar to that developed by Razran (1939) and employed by Bindra et al. (1955). This technique uses a small cotton roll under $\underline{S}^{\prime} \mathrm{s}$ tongue. The roll is weighed before and after use and the increase in weight is taken as the measure of salivation. All weight determinations, in milligrams, were made on a Troemner class I-B torsion balance. The UCS was a lemonflavoured Iollipop. The CS was a clearly audible pure tone of $2000 \mathrm{cps}$ lasting 30 seconds, presented by way of two tandem 4" speakers mounted under the table (Brogdin, 1947).

The Ss were conditioned $1 \frac{1}{2}-2$ hours after their noon meal. Each S was told:

We are studying the effects of various things such as noise, eating and reading upon digestion. I want you to sit quite relaxed. Here is a magazine, which you are to read. From time to time I will put a small cotton roll under your tongue. I will want you to rinse your mouth with water and later on you will have a sucker which I will want you to suck on. 
The mouth rinse ${ }^{2}$ of Iukewarm tap water was employed in an attempt to standardize the residual saliva level in the mouth and to remove sugar traces remaining after termination of the UCS.

Each $\underline{S}$ was given 64 trials, divided into three parts: a control series, an acquisition series and an extinction series. Each of the six control trials required $\underline{\mathrm{S}}$ to rinse his mouth out; $30 \mathrm{sec}$. later a cotton roll was placed under his tongue; $15 \mathrm{sec}$. Iater the CS was presented for a period of $30 \mathrm{sec} . ; 15 \mathrm{sec}$. after termination of the CS the cotton roll was removed for weighing.

The acquisition series consisted of 40 conditioning trials and 5 test trials; one test trial was given after every eight conditioning trials. S was given a lollipop and was told to put it in his mouth and to start sucking on it when the tone came on and to keep sucking on it until the tone stopped. The $\underline{S} s$ were warned not to bite ${ }^{3}$ or to chew the sucker and were supplied with new ones as required. When the tone terminated $\underline{S}$ was requested to remove the sucker and to rinse his mouth. The procedure for each test trial was the same as for the control trials. The sucker was taken from $\underline{S}$ after the last acquisition trial.

The extinction series consisted of 13 trials, the first and last

2 The author is indebted to Dr. D. Bindra for this suggestion. Information regarding the general effect of a water mouth rinse on saliva secretion is given in Appendix $B$.

3 Three chronic psychotics promptly chewed up all lollipops given to them so that salivation conditioning appeared impractical. Therefore, the UCS was withdrawn and these Ss were given 55 trials with the CS alone, with every fifth one being a control trial. Information on these $\underline{S}$ is given in the results. 
three being test trials. The inter-trial interval in all series was one min. The interval between the control and acquisition series was two min. and between the acquisition and extinction series it was five min.

Results

The data were analysed using $t$ ratios (the significance of each $\underline{t}$ ratio was assessed by a two-tailed test). Because the test results of the two groups were not homogeneous with regard to variance a nonparametric analysis was also done. This inquiry, using Kruskal-Wallis and Wilcoxon tests (Siegel, 1956), provided equivalent information and suggested, therefore, that the parametric analysis was reliable. Actuarial

Table I summarizes the information regarding age, education and intelligence for the two groups. Both groups had received comparable education and were of similar intelligence. However, the normals were significantly younger $(\underline{t}=3.67, p<.01)$ than the chronics. In view of this difference, product-moment correlations between age and all other variables were determined for each group. These correlations were uniformly low and none reached significance. Following Hilgard and Marquis $(1940, p .140)$ the age difference was therefore assumed to be of minor importance and was not further analysed. Test Performance

Information regarding three parameters: neuroticism, anxiety and psychoticism, is presented in Table II which also gives the $\underline{t}$ ratios between the group means. Neither group was found to be neurotic (BST) nor highly anxious (MAS), both performing within normal limits (Eysenck, 1952a; Taylor, 1953). 
Table I

Age, Education and IQ: Means and Standard Deviations

of Normals and Chronic Psychotics

\begin{tabular}{|c|c|c|c|c|c|c|}
\hline \multirow{2}{*}{ Variable } & \multicolumn{2}{|c|}{$\begin{array}{r}\text { Normals } \\
(\mathrm{N}=24)\end{array}$} & \multicolumn{3}{|c|}{ Chronic Psychotics } & \multirow{2}{*}{$\underline{t}$} \\
\hline & $\overline{\mathbf{X}}$ & SD & $\mathrm{N}$ & $\overline{\mathrm{X}}$ & SD & \\
\hline Age & 33.38 & 10.24 & 29 & 43.00 & 8.48 & $3.67 * *$ \\
\hline Education (years) & 7.96 & 6.05 & 26 & 8.19 & 2.29 & 0.34 \\
\hline IQ & 95.21 & 11.69 & 17 & 93.18 & 13.81 & 0.50 \\
\hline
\end{tabular}

$* * \mathrm{p}<.01$ 
Table II

Objective Tests: Means and Standard Deviations

of Normals and Chronic Psychotics

\begin{tabular}{|c|c|c|c|c|c|c|c|}
\hline \multirow{2}{*}{ Test } & \multicolumn{3}{|c|}{ Normals } & \multicolumn{3}{|c|}{ Chronic Psychotics } & \multirow{2}{*}{$\underline{t}$} \\
\hline & $\mathrm{N}$ & $\overline{\mathbf{X}}$ & SD & $\mathrm{N}$ & $\overline{\mathbf{x}}$ & SD & \\
\hline MAS & 20 & 19.15 & 9.51 & 15 & 14.20 & 9.84 & 1.46 \\
\hline BST & 20 & 2.19 & 2.96 & 16 & 0.73 & 2.01 & 1.86 \\
\hline $3 C$ & 24 & 8.96 & 6.65 & 19 & 23.79 & 16.22 & $3.97 * *$ \\
\hline IP & 23 & 125.56 & 242.44 & 19 & 51.05 & 31.26 & $3.88 * *$ \\
\hline VF & 24 & 17.50 & 6.48 & 19 & 10.21 & 6.76 & $3.51 * *$ \\
\hline TAP & 24 & 103.87 & 11.10 & 17 & 79.76 & 17.75 & $5.21 * * *$ \\
\hline \multicolumn{8}{|l|}{$\mathrm{RT}$} \\
\hline SRI & 24 & 25.67 & 4.64 & 14 & 43.79 & 17.55 & $3.78 * *$ \\
\hline SII & 24 & 25.31 & 3.49 & $u_{4}$ & 46.39 & 22.85 & $3.42 * x$ \\
\hline DII & 24 & 31.20 & 5.26 & 14 & 45.91 & 14.32 & $3.70 * *$ \\
\hline DRI & 24 & 32.01 & $4 \cdot 12$ & 14 & 45.79 & 14.18 & $3.55 *$ \\
\hline & & & & & & & \\
\hline
\end{tabular}

$* * \quad p<.01$ 
Each of the five objective performance tests employed to assess psychotic illness discriminated significantly $(\mathrm{p}<.01)$ between the normals and the chronics. The chronics spent more time in completing the 3C test $(\underline{t}=3.97)$, showed shorter IP $(\underline{t}=3.88)$, spoke fewer words on the VF test $(\underline{t}=3.51)$, evidenced a lower rate on the TAP test $(\underline{t}=5.21)$, and had longer $\mathrm{RT}^{4}(\underline{t}=3.42)$ than the normals.

Thus the two groups were found to be comparable with respect to education, intelligence, neuroticism and anxiety but differed significantly on five objective performance tests, giving support to the psychiatric grouping.

\section{Conditioning}

The conditioning data were examined in terms of both level scores and change scores. Level scores were performance means over blocks of control or acquisition or extinction trials, and change scores were mean differences between level scores. The important characteristics of such scores have been pointed out by Schnore (1959, p. 121) and their interdependence has been noted by Jenkins and Lykken (1957, p. 94). In general it appears that, while conditioning performance may be best evaluated using change scores, inter-group comparisons require that the level scores be comparable.

GSR. Tables III and IV give comparisons between the two groups for CRs recorded during acquisition and extinction trials. Although

4 It is of interest to note that, while each of the four RT procedures discriminated significantly between the two groups, the use of an irregular, ready signal, interval had no effect on RT for either group relative to their performance under regular warning intervals. A significant difference between simple and disjunctive RT, reflecting task difficulty, was found only with the normals. 
Table III

GSR Conditioning: Means and Standard Deviations of CRs of Normals and Chronic Psychotics

\begin{tabular}{c|cc|ccc}
\hline \multirow{2}{*}{ Trials } & \multicolumn{2}{|c|}{$\begin{array}{c}\text { Normals } \\
(\mathrm{N}=13)\end{array}$} & \multicolumn{2}{c}{$\begin{array}{c}\text { Chronic Psychotics } \\
(\mathrm{N}=18)\end{array}$} & $\mathrm{t}$ \\
\cline { 2 - 6 } & $\overline{\mathrm{x}}$ & $\mathrm{SD}$ & $\overline{\mathrm{x}}$ & $\mathrm{SD}$ & \\
\hline Acquisition 1-10 & 5.04 & 3.08 & 3.39 & 2.96 & 1.46 \\
Extinction 1-10 & 4.62 & 2.37 & 3.33 & 2.52 & 1.39 \\
Extinction 11-20 & 2.15 & 1.75 & 1.67 & 1.45 & 0.82 \\
\hline
\end{tabular}

Table IV

GSR Conditioning: Mean Difference Scores and Standard Errors of CRs of Normals and Chronic Psychotics

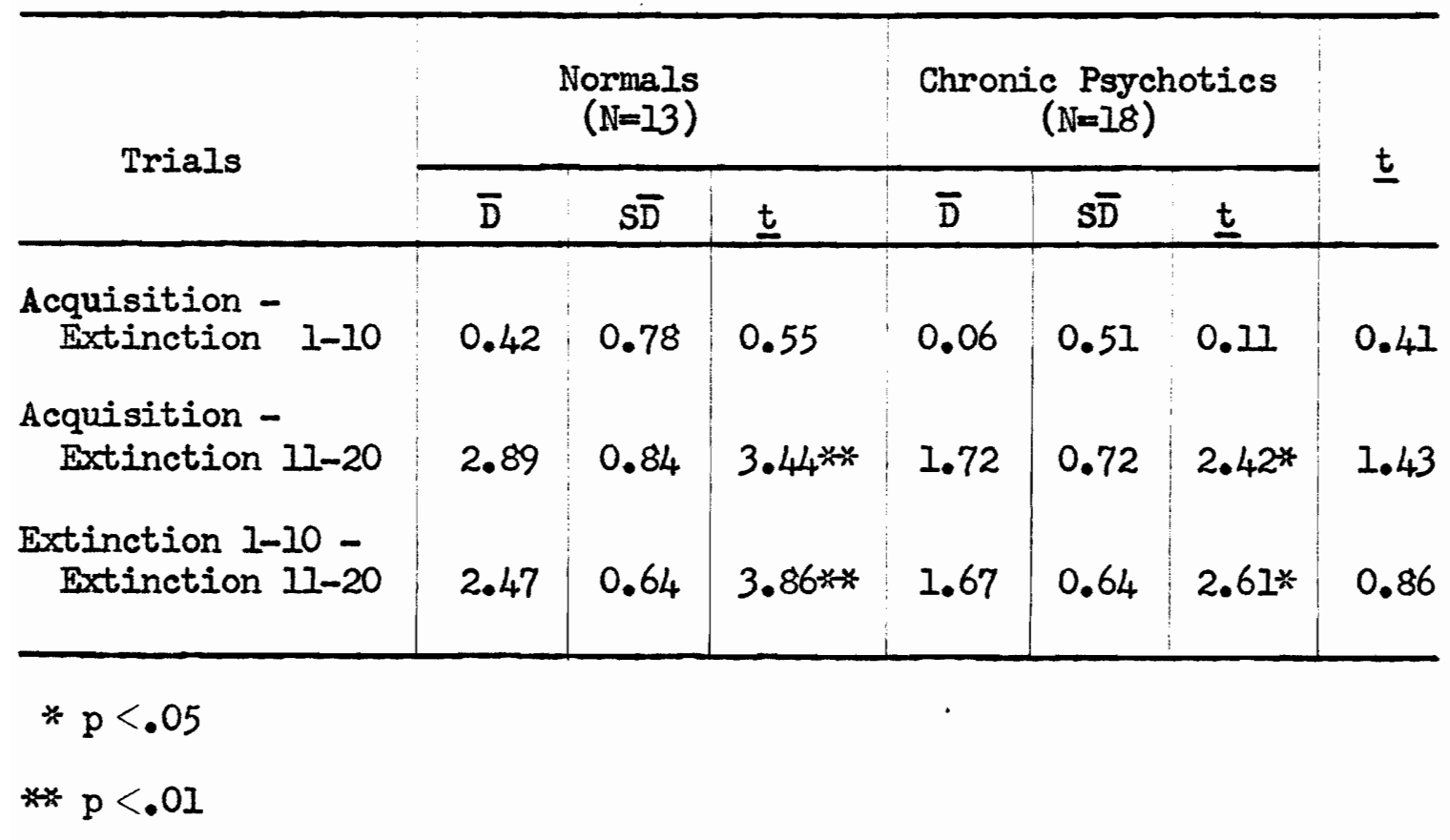


the normals tended to give CRs more frequently than did the chronics, the response levels were not significantly $(p>.05)$ different (Table III). The extinction rates for both groups were significant (Table IV), and were found to be similar. It may be noted, however, that a higher level of confidence $(\underline{t}=3.44, p<.01)$ was associated with the normal extinction curve than with that of the chronics $(\underline{t}=2.42, p<.05)$.

This latter observation suggested that the GSR conditioning situation might have affected the two groups differentially. However, an examination of initial and final log conductance measures and UCS intensities (Table V) revealed no significant inter-group differences.

Verbal. The mean operant, acquisition and extinction levels (Table VI) were similar for both groups. The performance curves of the chronic and normal groups did not differ significantly but the chronic group failed to show significant effects contingent upon reinforcement (Table VII). The normals, on the other hand, evidenced significant acquisition (operant - acquisition, $\underline{t}=3.25, \mathrm{p}<.05$; operant - extinction, $\underline{t}=2.85, \mathrm{p}<.05)$ but showed no reliable extinction effects.

Salivation. Table VIII presents mean control, acquisition and extinction trial salivation levels for each group. The normals were found to have secreted significantly more saliva during the control trials $(\underline{t}=2.67, p<.05)$ and during the first three extinction trials $(\underline{t}=2.20, \mathrm{p}<.05)$ than had the chronics.

Significant acquisition (increment, control - acquisition) and significant extinction (decrement, acquisition - extinction trials II 13) occurred with each group (Table IX). In order to test whether the two groups responded differently during the acquisition trials, the 
Table V

GSR Conditioning: Means and Standard Deviations

of Log Conductance $\left(\begin{array}{l}x \\ 10^{2}\end{array}\right)$ and Shock Levels

of Normals and Chronic Psychotics

\begin{tabular}{|c|c|c|c|c|c|}
\hline \multirow{2}{*}{ Variable } & \multicolumn{2}{|c|}{$\begin{array}{r}\text { Normals } \\
(N=13)\end{array}$} & \multicolumn{2}{|c|}{$\begin{array}{c}\text { Chronic Psychotics } \\
(N=18)\end{array}$} & \multirow{2}{*}{$\underline{t}$} \\
\hline & $\overline{\mathrm{X}}$ & $S D$ & $\overline{\mathbf{z}}$ & SD & \\
\hline $\begin{array}{l}\text { Initial log } \\
\text { conductance }\end{array}$ & 562.11 & 18.61 & 581.90 & 25.42 & 0.63 \\
\hline $\begin{array}{l}\text { Final log } \\
\text { conductance }\end{array}$ & 543.93 & 16.84 & 558.00 & 19.33 & 0.55 \\
\hline Shock level & 4.30 & 1.62 & 4.43 & 1.51 & 0.22 \\
\hline
\end{tabular}

Table VI

Verbal Conditioning: Means and Standard Deviations

of "She" and "We" Responses (Combined)

of Normals and Chronic Psychotics

\begin{tabular}{l|ccccc|c}
\hline \multirow{2}{*}{ Trial Series } & \multicolumn{2}{|c}{$\begin{array}{c}\text { Normals } \\
(\mathrm{N}=10)\end{array}$} & \multicolumn{3}{c}{$\begin{array}{c}\text { Chronic Psychotics } \\
(\mathrm{N}=9)\end{array}$} & \multirow{2}{*}{$\mathrm{t}$} \\
\cline { 2 - 6 } & $\overline{\mathrm{X}}$ & $\mathrm{SD}$ & \multicolumn{1}{c}{$\overline{\mathrm{x}}$} & $\mathrm{SD}$ & \\
\hline Operant & 6.60 & 2.19 & 6.33 & 3.50 & 0.19 \\
Acquisition & 8.41 & 2.06 & 7.43 & 3.64 & 0.68 \\
Extinction & 9.14 & 2.16 & 8.42 & 4.51 & 0.42 \\
\hline
\end{tabular}


Table VII

Verbal Conditioning: Mean Difference Scores and Standard Errors of "She" and "We" Responses (Combined) of Normals and Chronic Psychotics

\begin{tabular}{l|c|c|c|c|c|c|c}
\hline \multirow{2}{*}{ Trials } & \multicolumn{3}{|c|}{$\begin{array}{c}\text { Normals } \\
(\mathrm{N}=10)\end{array}$} & \multicolumn{3}{c|}{$\begin{array}{c}\text { Chronic Psychotics } \\
(\mathrm{N}=9)\end{array}$} & \multirow{2}{*}{$\mathrm{t}$} \\
\cline { 2 - 6 } & $\overline{\mathrm{D}}$ & $\mathrm{S} \overline{\mathrm{D}}$ & $\underline{\mathrm{t}}$ & $\overline{\mathrm{D}}$ & $\mathrm{SD}$ & $\underline{\mathrm{t}}$ & \\
\hline $\begin{array}{c}\text { Operant - } \\
\text { Acquisition }\end{array}$ & -1.81 & 0.53 & $3.25 *$ & -1.10 & 1.19 & 0.93 & 0.55 \\
$\begin{array}{c}\text { Operant - } \\
\text { Extinction } \\
\begin{array}{c}\text { Acquisition - } \\
\text { Extinction }\end{array}\end{array}$ & -2.54 & 0.89 & $2.85 *$ & -2.09 & 1.32 & 1.58 & 0.88 \\
\hline
\end{tabular}

* $\mathrm{p}<.05$

Table VIII

Salivation Conditioning: Means and Standard Deviations (Mg. Saliva) of Normals and Chronic Psychotics

\begin{tabular}{|c|c|c|c|c|c|}
\hline \multirow{2}{*}{ Trials } & \multicolumn{2}{|c|}{$\begin{array}{r}\text { Normals } \\
(\mathrm{N}=24)\end{array}$} & \multicolumn{2}{|c|}{$\begin{array}{l}\text { Chronic Psychotics } \\
\qquad(\mathrm{N}=26)\end{array}$} & \multirow{2}{*}{$\underline{t}$} \\
\hline & $\overline{\mathrm{X}}$ & $\mathrm{SD}$ & $\overline{\mathbf{X}}$ & $\mathrm{SD}$ & \\
\hline ControI & 506.58 & 244.34 & 333.24 & 204.81 & $2.67 *$ \\
\hline Acquisition & 622.74 & 289.89 & 541.00 & 284.68 & 1.47 \\
\hline Extinction $(1-3)$ & 627.90 & 341.10 & 436.22 & 258.92 & $2.20 *$ \\
\hline Extinction (11-13) & 513.66 & 282.61 & 474.22 & 265.94 & 1.25 \\
\hline
\end{tabular}


Table IX

Salivation Conditioning: Mean Difference Scores and Standard Errors

(Mg. Saliva) of Normals and Chronic Psychotics

\begin{tabular}{|c|c|c|c|c|c|c|c|}
\hline \multirow{2}{*}{ Trials } & \multicolumn{3}{|c|}{$\begin{array}{r}\text { Normals } \\
(\mathrm{N}=24)\end{array}$} & \multicolumn{3}{|c|}{$\begin{array}{l}\text { Chronic Psychotics } \\
\qquad(\mathrm{N}=26)\end{array}$} & \multirow{2}{*}{$\underline{t}$} \\
\hline & $\overline{\mathrm{D}}$ & $S \bar{D}$ & $\underline{t}$ & $\overline{\mathrm{D}}$ & $S \bar{D}$ & $\underline{t}$ & \\
\hline $\begin{array}{l}\text { Control - } \\
\text { Acquisition }\end{array}$ & -116.16 & 41.25 & $2.82 * x *$ & -207.76 & 31.66 & $6.56 * *$ & 1.78 \\
\hline $\begin{array}{l}\text { Control - } \\
\quad \text { Extinction 11-13 }\end{array}$ & -7.08 & 37.37 & 0.19 & -80.98 & 33.23 & $2.44 *$ & 1.40 \\
\hline $\begin{array}{l}\text { Acquisition - } \\
\text { Extinction } 1-3\end{array}$ & -5.16 & 38.72 & 0.13 & 104.78 & 18.98 & $5.52 * *$ & $2.29 *$ \\
\hline $\begin{array}{l}\text { Acquisition - } \\
\text { Extinction 11-13 }\end{array}$ & 109.08 & 39.69 & $2.77 *$ & 126.78 & 30.15 & $4.21 * *$ & 0.48 \\
\hline $\begin{array}{l}\text { Extinction } 1-3-\overline{3} \\
\text { Extinction } 11-1 \overline{3}\end{array}$ & 114.24 & 31.74 & $3.60 * *$ & 22.00 & 22.53 & 0.98 & $2.36 *$ \\
\hline
\end{tabular}

$* \mathrm{p}<.05$

$* * \mathrm{p}<.01$ 



to or higher than their group median control level were determined. The difference between these independent proportions was then tested with $x^{2}$ which yielded a value of $1.82, p>.10$, indicating that the acquisition rates were similar for both groups. The reliability of these data was supported by the results of the three chronic psychotics who were tested without lollipops, no significant change being observed in their 11 control means over the two hours of testing.

Withdrawal of reinforcement during the extinction trials had a differential effect upon the two groups. The chronics evidenced immediate response decrement whereas the normals tended to maintain their acquisition level over the first extinction trials. Although the final salivation levels of the two groups did not differ, the final level of the chronics was significantly $(\underline{t}=2.44, p<.05)$ higher than their control level. On the other hand, the final level of the normals was found not to differ from their control level.

Analysis of Conditionability. In order to remove the effects of level from the rate data, regression scores ${ }^{5}$ were computed for both acquisition and extinction slopes for each of the conditioning procedures. Product-moment correlations were computed between the three conditioning procedures using levels, between-level differences, and regression scores for the normals and the chronics. Since none of the inter-conditioning relationships was significant no evidence for a

\footnotetext{
5 The formula employed was: $x_{2}^{\prime}=r_{12} \frac{S_{2}}{S_{1}}\left(x_{1}-\bar{x}_{1}\right)+\bar{x}_{2}$, the regression score being $x_{2}-x_{2}^{\prime}$
} 
factor of conditionability was found.

\section{Effects of Severity of Psychosis}

In view of the differences in objective test performance between the normals and the chronics, it was assumed that the test scores could be taken as measures of severity of illness. In the light of this assumption, product-moment correlations were computed between the test scores of the chronic psychotics and their conditioning rates.

None of the correlations was significant. It was then decided to repeat the correlational analysis using years in institution as an index of severity. This analysis likewise was without significant results.

Summary of Results

Significant conditioning effects under GSR and salivation procedures were obtained with both groups. Under the verbal conditioning task only the normal group evidenced significant response acquisition. Analysis of the acquisition curves did not reveal any significant intergroup differences. The salivation extinction data indicated that the two groups were responding differentially in that the normals tended to return to response levels held prior to conditioning, whereas the chronics tended to perseverate acquisition effects.

The main finding from the study, therefore, was that the conditioning performance of chronic psychotics differs from that of normals. The differences found may have occurred because the patients were psychotic, chronic and/or institutionalized.

In order to assess these factors more fully, Study II was conducted. This second investigation was planned so as to control for insti- 
tutionalization effects by using penitentiary inmates (institutionalized non-psychotics) and acute psychotics (non-institutionalized


to provide information regarding the acute - chronic dimension as well as to provide for cross validation of the results of Study $I$. 


\section{STUDY II}

\section{Method}

\section{Subjects}

Three groups of male $\underline{S} s^{6}$ were tested. Group I consisted of inmates in a penitentiary. Random selection not being possible, a brief statement requesting volunteers was read to all prisoners. Thirty-eight $\underline{\text { Ss }}$ volunteered, of whom four were eliminated from the study: two because they had received psychiatric care and two because they completed only the initial tests. The remaining 34 ss had been in the institution for a mean period of 11.42 months (S.D. $=10.37$ ). Detailed descriptive information regarding these inmates is given in Appendix C.

Group II consisted of $3 I$ Ss who were seen within two weeks of their first admission to a large mental hospital. AII Ss had been diagnosed as psychotic and were not organically impaired; nor had they received any physical treatment within the preceding four months.

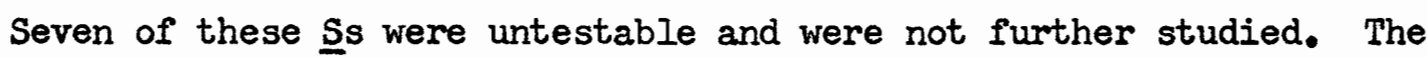
conference diagnoses of the remaining 24 patients were schizophrenia, 23; manic depressive, depressed, 1.

Group III consisted of 24 patients from the chronic wards of a large mental hospital, diagnosed as schizophrenic, all of whom met the selection criteria used in Study I. The mean number of years in hospital for this group was 11.00 (S.D. $=5.25$ ). Prior to testing, each patient in Groups II and III was withdrawn from aII medication for a period of five days.

6 Information regarding age and education is given in Table $\mathrm{x}$. 


\section{Procedure and Apparatus}

Each $\underline{S}$ was seen individually, once in the morning and once in the afternoon. The tests used and their order of administration were the same as in Study I except that due to lack of equipment the BST and RT test were not available. The Maudsley Personality Inventory (MPI) (Eysenck, 1959) was introduced in place of the BST to provide information regarding neuroticism levels, and was administered after the VF test.

The inmate group, although resident in a different institution from the patients, were tested under similar physical arrangements. Wherever possible all apparatus used in Study II was similar to or identical with that used in Study I; exceptions are itemized below:

Tone. Tones for both the GSR and salivation procedures were generated by an Audivox $7 B$ audiometer which had headphones matched to it, rated in decibels $(\mathrm{db})$ at the ear. Only the phone to the ear indicated by the $\underline{S}$ as his preferred ear was used (Iittman, 1949), the other ear being covered with a dummy phone to balance the head set.

Shock and timer. A full wave variable intensity shock apparatus was constructed, together with a variable interval timer (see Appendix D). The shock circuit consisted of a condenser which could be discharged across the primary coil of a small transformer. A variable resistor calibrated from 0 - 900 volts controlled the shock intensity, the time base of which was constant and approximately $50 \mathrm{~ms}$. The timing circuit employed a relay controlled by condenser discharge and was variable over the range $1-9 \mathrm{sec}$.

GSR. A portable, direct reading GSR amplifier was constructed 
(see Appendix D) to duplicate one obtained on Ioan. ${ }^{7}$ This unit employed a standard voltage comparator bridge with a constant current $( \pm 2 \%)$. DC skin resistance values were read directly from a one-milliamp meter calibrated in ohms. Each S's auditory threshold for the CS was estabIished at his preferred ear by the method of limits. The CS used was a pure tone of $500 \mathrm{cps}$, this frequency being the closest one available on the Audivox to that used in Study $I$. The threshold value obtained was then increased by $35 \mathrm{db}$ (Kimmel, 1959), and remained at that level throughout the conditioning procedure. A CR was scored during the 10 test trials and the 20 extinction trials if a resistance drop was observable within a period of $2-5$ sec. following onset of the CS. Salivation conditioning. Following preliminary instructions, each S's auditory threshold for the CS (tone of $2000 \mathrm{cps}$ ) was determined as above, and then increased by $35 \mathrm{db}$. The procedure then followed that earlier described.

Results

As in Study I, the data were analysed twice, once by parametric and once by nonparametric procedures. The two analyses yielded similar information. Therefore, only the parametric analysis is reported. Actuarial

Table $X$ summarizes the information regarding age, education and intelligence for the three groups. The inmates were younger $(\underline{t}=2.25$, $p<.05)$ than the acutes and the acutes were younger $(\underline{t}=4.27, p<.01)$ than the chronics. The inmates, while more intelligent $(\underline{t}=2.06$,

7 The author wishes to express hi.s indebtedness to Dr. R.B. Malmo, Allan Memorial Institute of Psychiatry, for the generous Ioan of this equipment. 


\section{Table X}

Age, Education and IQ: Means and Standard Deviations of Inmates, Chronic Psychotics and Acute Psychotics

\begin{tabular}{|c|c|c|c|c|c|c|c|c|c|}
\hline \multirow{2}{*}{ Variable } & \multicolumn{2}{|c|}{$\begin{array}{c}\text { Inmates } \\
(\mathrm{N}=34)\end{array}$} & \multicolumn{2}{|c|}{$\begin{array}{l}\text { Chronic } \\
\text { Psychotics } \\
(\mathrm{N}=24)\end{array}$} & \multicolumn{2}{|c|}{$\begin{array}{c}\text { Acute } \\
\text { Psychotics } \\
(\mathrm{N}=24)\end{array}$} & \multicolumn{3}{|c|}{$\underline{t}$} \\
\hline & $\overline{\mathrm{x}}$ & SD & $\overline{\mathbf{X}}$ & $S D$ & $\overline{\mathbf{X}}$ & $S D$ & $\begin{array}{l}\text { Inmate } \\
\text { Chronic }\end{array}$ & $\begin{array}{r}\text { Inmate } \\
\text { Acute }\end{array}$ & $\begin{array}{c}\text { Chronic } \\
\text { Àcute }\end{array}$ \\
\hline Age & 24.56 & 7.57 & 39.75 & 10.14 & 28.96 & 6.67 & $6.42 * *$ & $2.25 \%$ & $4.27 * *$ \\
\hline $\begin{array}{r}\text { Education } \\
\text { (years) }\end{array}$ & 9.32 & 1.84 & 8.70 & 2.44 & 9.41 & 1.81 & 1.22 & 0.19 & 1.25 \\
\hline$I Q$ & 100.00 & 9.00 & 94.08 & 12.52 & 97.96 & 0.04 & $2.06 *$ & 0.83 & 1.20 \\
\hline
\end{tabular}

$$
\begin{aligned}
& * \mathrm{p}<.05 \\
& * * \mathrm{p}<.01
\end{aligned}
$$


$\mathrm{p}<.05)$ than the chronics, did not differ in this respect from the acutes. In order to assess the importance of these differences, product-moment correlations were computed between age and intelligence and the main conditioning variables for each group. None of these correlations was significant; therefore, neither age nor intelligence appeared to warrant further investigation.

\section{Test Performance}

Information regarding anxiety, extraversion, neuroticism and psychoticism is given in Table XI, which also presents the $\underline{t}$ ratios between the group means. There were no significant differences in anxiety levels (MAS) between the three groups and the mean anxiety scores were within the normal range (Taylor, 1953). The inmates were found to be significantly $(\underline{t}=2.64, p<.05)$ more extraverted than the acute psychotics and significantly $(\underline{t}=2.70, p<.01)$ more neurotic than the chronics. The acute and chronic groups were found not to differ on either measure.

Product-moment correlations were computed between the extraversion and neuroticism scores and conditioning measures for each group. None of these correlations was found to be significant.

Each of the four objective performance tests employed to assess psychoticism discriminated significantly $(p<.0 I)$ between the inmates and the chronics. The chronics took longer to complete the $3 \mathrm{C}$ test $(\underline{t}=6.35)$, showed shorter IP $(\underline{t}=3.57)$, spoke fewer words on the VF test $(\underline{t}=7.88)$ and evidenced a lower rate on the TAP test $(\underline{t}=5.93)$ than did the inmates. Similar discriminations between the inmates and the acutes were obtained with three tests: $3 C(\underline{t}=5.94), V F(\underline{t}=2.74)$ 
Table XI

Objective Tests: Means and Standard Deviations of

Inmates, Chronic Psychotics and Acute Psychotics

\begin{tabular}{|c|c|c|c|c|c|c|c|c|c|c|c|}
\hline \multirow{2}{*}{ Test } & \multicolumn{2}{|c|}{$\begin{array}{c}\text { Inmates } \\
(\mathrm{N}=34)\end{array}$} & \multicolumn{3}{|c|}{$\begin{array}{l}\text { Chronic } \\
\text { Psychotics }\end{array}$} & \multicolumn{3}{|c|}{$\begin{array}{c}\text { Acute } \\
\text { Psychotics }\end{array}$} & \multicolumn{3}{|c|}{$\underline{t}$} \\
\hline & $\overline{\mathrm{x}}$ & $\mathrm{SD}$ & $\mathrm{N}$ & $\overline{\mathrm{X}}$ & SD & $\mathrm{N}$ & $\overline{\mathbf{X}}$ & SD & $\begin{array}{l}\text { Inmate } \\
\text { Chronic }\end{array}$ & $\begin{array}{c}\text { Inmate } \\
\text { Acute }\end{array}$ & $\begin{array}{c}\text { Chronic } \\
\text { Acute }\end{array}$ \\
\hline MAS & 18.03 & 8.10 & 20 & 16.74 & 10.66 & 24 & 19.65 & 7.34 & 0.48 & 0.75 & 1.02 \\
\hline MPI (E) & 28.03 & 7.55 & 18 & 23.35 & 8.77 & 16 & 21.71 & 6.85 & 1.92 & $2.64 *$ & 0.55 \\
\hline $\operatorname{MPI}(N)$ & 31.06 & 11.43 & 18 & 21.52 & 11.86 & 16 & 24.07 & 12.43 & $2.70 * * *$ & 1.82 & 0.56 \\
\hline $3 c$ & 6.33 & 2.68 & 24 & 17.82 & 9.69 & 24 & 16.30 & 8.91 & $6.35 * *$ & $5.94 * * *$ & 0.54 \\
\hline LP & 87.06 & 42.70 & 24 & 50.35 & 27.27 & 24 & 70.13 & 58.10 & $3.57 \div$ & 1.23 & 1.45 \\
\hline $\mathrm{VF}$ & 24.09 & 5.63 & 24 & 10.65 & 6.86 & 24 & 18.91 & 8.25 & $7.88 * *$ & $2.74 * *$ & $3.61 * *$ \\
\hline TAP & 101.69 & 11.50 & 24 & 75.39 & 20.87 & 24 & 79.04 & 20.66 & $5.93 * *$ & $5.15 * *$ & 0.58 \\
\hline
\end{tabular}

$* p<.05$

** $\mathrm{p}<.01$ 
and TAP $(\underline{t}=5.15)$. The two psychotic groups differed significantly only on the VF test $(\underline{t}=3.6 I, p<.0 I)$, the acutes speaking more words.

The significant differences between the inmates and psychotics on the objective performance tests is in agreement with many previous studies (Amin, 1960; Benton, Jentsch and Wahler, 1959; Eysenck, 1952b; Rosenbaum, Mackavey and Grise11, 1957; Stolsky, 1957) and supports the psychiatric groupings used. Conditioning

GSR. Table XII summarizes the GSR conditioning performance of the three groups. Response levels were similar and none of the inter-group differences was significant. Extinction rates (decrement, acquisition - extinction) were significant for each group (Table XIII). The extinction curves of the inmates and acutes were comparable. These two groups, however, were both more resistant to extinction during the first 10 extinction trials than were the chronics (inmate $\underline{t}=2.11$, $p<.05$; acute $\underline{t}=3.01, p<.01$ ). Significant extinction effects for the acutes were observed only during the last 10 extinction trials, during which their extinction rate was more rapid $(\underline{t}=2.36, p<.05)$ than that of the chronic psychotics.

Table XIV presents an analysis of the initial and final log conductance measures for each group, together with information covering shock intensities used. It may be seen from this table that the inmate group had an initial conductance level that was higher than either the chronics $(\underline{t}=3.41, p<.01)$ or the acutes $(\underline{t}=3.49, p<.01)$. The inmates also evidenced a higher final conductance level than did the acutes $(\underline{t}=2.19, p<.05)$. Only one of the inter-group differences in 
Table XII

GSR Conditioning: Means and Standard Deviations of CRs of

Inmates, Chronic Psychotics and Acute Psychotics

\begin{tabular}{|c|c|c|c|c|c|c|c|c|c|}
\hline \multirow[t]{2}{*}{ Trials } & \multicolumn{2}{|c|}{$\begin{array}{r}\text { Inmates } \\
(\mathrm{N}=32)\end{array}$} & \multicolumn{2}{|c|}{$\begin{array}{l}\text { Chronic } \\
\text { Psychotics } \\
(N=17)\end{array}$} & \multicolumn{2}{|c|}{$\begin{array}{c}\text { Acute } \\
\text { Psychotics } \\
(\mathrm{N}=20)\end{array}$} & \multicolumn{3}{|c|}{$\underline{t}$} \\
\hline & $\overline{\mathrm{x}}$ & SD & $\overline{\mathrm{X}}$ & $\mathrm{SD}$ & $\overline{\mathrm{X}}$ & SD & $\begin{array}{l}\text { Inmate } \\
\text { Chronic }\end{array}$ & $\begin{array}{r}\text { Inmate } \\
\text { Acute }\end{array}$ & $\begin{array}{c}\text { Chronic } \\
\text { Acute }\end{array}$ \\
\hline $\begin{array}{l}\text { Acquisition } \\
1-10\end{array}$ & 4.54 & 3.20 & 4.08 & 2.48 & 3.98 & 2.80 & 0.50 & 0.62 & 0.12 \\
\hline $\begin{array}{l}\text { Extinction } \\
1-10\end{array}$ & 3.28 & 2.62 & 1.77 & 1.50 & 3.20 & 2.45 & 2.18 & 0.11 & 2.05 \\
\hline $\begin{array}{l}\text { Extinction } \\
11-20\end{array}$ & 1.66 & 1.66 & 1.00 & 1.23 & 1.50 & 1.73 & 1.36 & 0.32 & 1.00 \\
\hline
\end{tabular}


Table XIII

GSR Conditioning: Mean Difference Scores and Standard Errors of CRs of Inmates, Chronic Psychotics and Acute Psychotics






\section{Table XIV}

GSR Conditioning: Means and Standard Deviations of $\log$ Conductance $\left(X 10^{2}\right)$ and Shock Voltage of Inmates, Chronic Psychotics and Acute Psychotics

\begin{tabular}{|c|c|c|c|c|c|c|c|c|c|}
\hline \multirow{2}{*}{ Variable } & \multicolumn{2}{|c|}{$\begin{array}{r}\text { Inmates } \\
(\mathrm{N}=32)\end{array}$} & \multicolumn{2}{|c|}{$\begin{array}{c}\text { Chronic } \\
\text { Psychotics } \\
(\mathrm{N}=17)\end{array}$} & \multicolumn{2}{|c|}{$\begin{array}{l}\text { Acute } \\
\text { Psychotics } \\
(\mathrm{N}=20)\end{array}$} & \multicolumn{3}{|c|}{$\underline{t}$} \\
\hline & $\overline{\mathbf{x}}$ & $S D$ & $\bar{x}$ & $\mathrm{SD}$ & $\overline{\mathrm{X}}$ & SD & $\begin{array}{l}\text { Inmate } \\
\text { Chronic }\end{array}$ & $\begin{array}{r}\text { Inmate } \\
\text { Acute }\end{array}$ & $\begin{array}{c}\text { Chronic } \\
\text { Acute }\end{array}$ \\
\hline $\begin{array}{l}\text { Initial log } \\
\text { conductance }\end{array}$ & 576.90 & 14.78 & 562.43 & 10.50 & 563.47 & 9.17 & $3.41 * *$ & $3.49 *-*$ & 0.36 \\
\hline $\begin{array}{l}\text { Final log } \\
\text { conductance }\end{array}$ & 579.96 & 19.01 & 572.06 & 15.97 & 569.21 & 11.20 & 1.39 & $2.19 *$ & 0.60 \\
\hline Shock voltage & 478.03 & 213.84 & 601.87 & 176.11 & 471.05 & 153.30 & 1.97 & 1.22 & $2.28 *$ \\
\hline
\end{tabular}

$* \mathrm{p}<.05$

*** $p<.01$ 
shock level was significant, the acute psychotics having received a higher level of shock $(\underline{t}=2.28, p<.05)$ than had the chronics. None of the correlations between the GSR conditioning measures (level, change or regression scores) and the conductance or shock values was significant.

Verbal. Verbal conditioning scores for the three groups are summarized in Table XV and analysed in Table XVI. None of the differences between groups was significant. Significant acquisition effects (increment, operant - acquisition, $t=3.17, \mathrm{p}<.01$ ) were obtained only with the acute psychotics. Extinction (decrement, acquisition extinction) was not evident with the acutes, and was not demonstrated with the inmates nor the chronics. This latter observation was to have been expected since neither group showed significant acquisition.

Salivation. Table XVII sumarizes the mean salivation control, acquisition and extinction trial levels for each of the three groups. None of the inter-group differences between mean trial levels was significant. Acquisition (increment, control - acquisition) and extinction (decrement, acquisition - extinction trials II - 13, or extinction trials $1-3$ and 11 - 13) were significant for each group (Table XVIII). The inmate group, however, evidenced a greater overall conditioning effect (increment, control - extinction trials 11 - 13) than did the acutes $(\underline{t}=2.41, p<.01)$. It should be noted that this slope was also positive and significant for the chronics $(\underline{t}=2.11, p<.05)$ but that it was not significant for the acutes (Table XVIII, line 2).

Analysis of conditionability. A correlational analysis of the relationships between the three types of conditioning for each of the three groups was made. This analysis was similar to the one reported 
Table XV

Verbal Conditioning: Means and Standard Deviations of "She" and "We" Responses

(Combined) of Inmates, Chronic Psychotics and Acute Psychotics

\begin{tabular}{|c|c|c|c|c|c|c|c|c|c|}
\hline \multirow[t]{2}{*}{ Trial Series } & \multicolumn{2}{|c|}{$\begin{array}{r}\text { Inmates } \\
(\mathrm{N}=32)\end{array}$} & \multicolumn{2}{|c|}{$\begin{array}{l}\text { Chronic } \\
\text { Psychotics } \\
(\mathrm{N}=14)\end{array}$} & \multicolumn{2}{|c|}{$\begin{array}{c}\text { Acute } \\
\text { Psychotics } \\
(\mathrm{N}=23)\end{array}$} & \multicolumn{3}{|c|}{$\underline{t}$} \\
\hline & $\overline{\mathrm{X}}$ & SD & $\overline{\mathrm{X}}$ & $S D$ & $\overline{\mathrm{X}}$ & SD & $\begin{array}{l}\text { Inmate } \\
\text { Chronic }\end{array}$ & $\begin{array}{r}\text { Inmate } \\
\text { Acute }\end{array}$ & $\begin{array}{c}\text { Chronic } \\
\text { Acute }\end{array}$ \\
\hline Operant & 7.56 & 2.31 & 6.79 & 2.76 & 6.26 & 3.76 & 0.94 & 1.56 & 0.45 \\
\hline Acquisition & 8.42 & 3.05 & 7.60 & 3.56 & 8.26 & 4.01 & 0.75 & 0.17 & 0.50 \\
\hline Extinction & 8.00 & 2.88 & 7.21 & 3.69 & 8.32 & 4.57 & 0.78 & 0.32 & 0.76 \\
\hline
\end{tabular}


Table XVI

Verbal Conditioning: Mean Difference Scores and Standard Errors of "She" and "We" Responses (Combined) of Inmates, Chronic Psychotics and Acute Psychotics

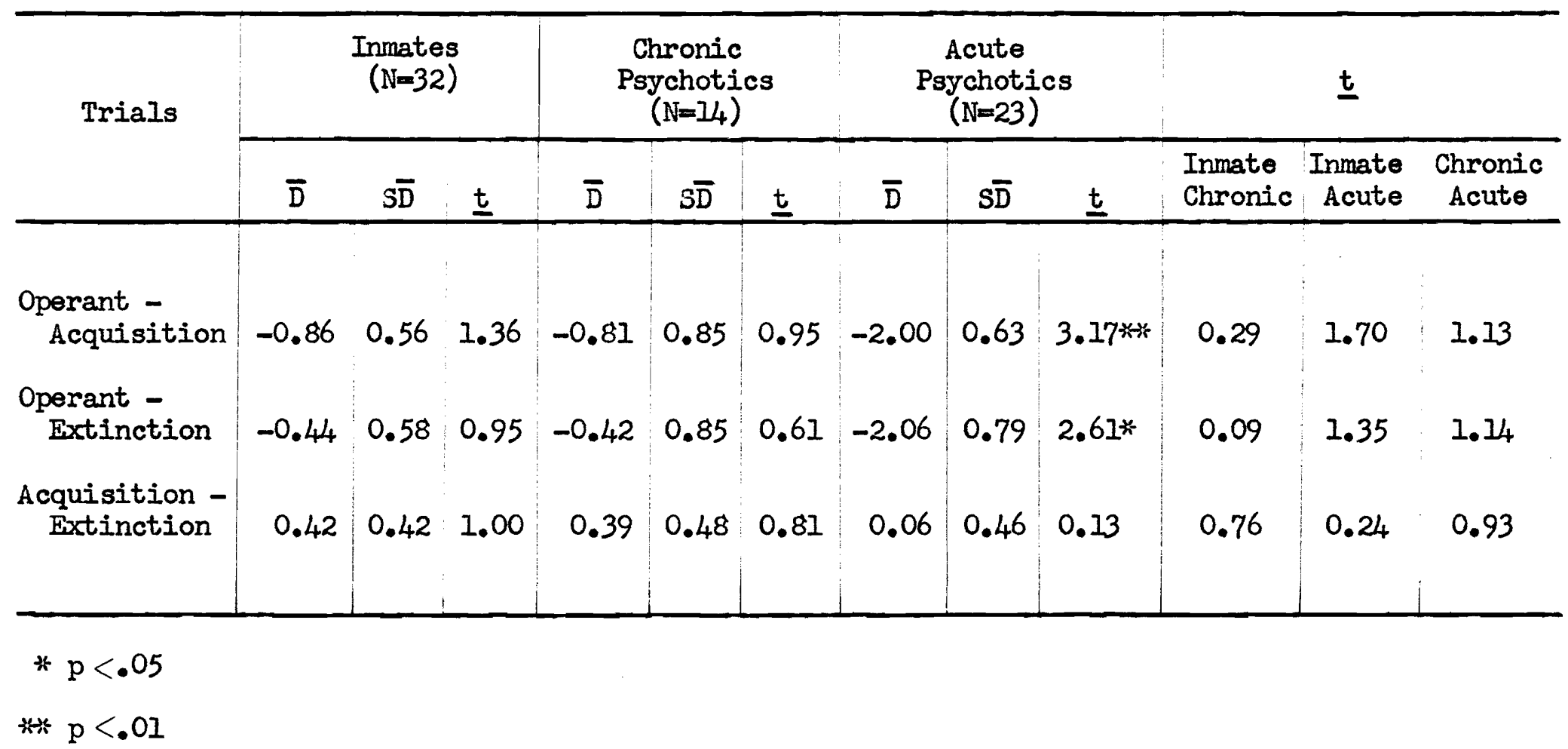




\section{Table XVII}

Salivation Conditioning: Means and Standard Deviations (Mg. Saliva)

of Inmates, Chronic Psychotics and Acute Psychotics

\begin{tabular}{|c|c|c|c|c|c|c|c|c|c|}
\hline \multirow[t]{2}{*}{ Trials } & \multicolumn{2}{|c|}{$\begin{array}{c}\text { Inmates } \\
(\mathrm{N}=31)\end{array}$} & \multicolumn{2}{|c|}{$\begin{array}{l}\text { Chronic } \\
\text { Psychotics } \\
(\mathrm{N}=23)\end{array}$} & \multicolumn{2}{|c|}{$\begin{array}{c}\text { Acute } \\
\text { Psychotics } \\
(\mathrm{N}=2 \mathrm{l})\end{array}$} & \multicolumn{3}{|c|}{$\underline{t}$} \\
\hline & $\overline{\mathbf{X}}$ & SD & $\overline{\mathrm{X}}$ & $\mathrm{SD}$ & $\overline{\mathrm{X}}$ & SD & $\begin{array}{l}\text { Inmate } \\
\text { Chronic }\end{array}$ & $\begin{array}{r}\text { Inmate } \\
\text { Acute }\end{array}$ & $\begin{array}{c}\text { Chronic } \\
\text { Acute }\end{array}$ \\
\hline Control & 244.18 & 182.27 & 282.68 & 327.08 & 379.80 & 168.42 & 0.12 & 1.90 & 1.09 \\
\hline Acquisition & 507.74 & 209.22 & 455.82 & 299.91 & 516.67 & 196.63 & 0.68 & 0.15 & 0.71 \\
\hline Extinction $(1-3)$ & 533.34 & 212.15 & 512.42 & 353.79 & 455.60 & 172.72 & 0.26 & 1.36 & 0.65 \\
\hline Extinction (11-13) & $454 \cdot 50$ & 170.96 & 379.90 & 239.72 & 406.67 & 146.34 & 1.31 & 0.44 & 1.01 \\
\hline
\end{tabular}




\section{Table XVIII}

Salivation Conditioning: Mean Difference Scores and Standard Errors

(Mg. Saliva) of Inmates, Chronic Psychotics and Acute Psychotics

\begin{tabular}{|c|c|c|c|c|c|c|c|c|c|c|c|c|}
\hline \multirow{3}{*}{ Trials } & \multirow{2}{*}{\multicolumn{3}{|c|}{$\begin{array}{r}\text { Inmates } \\
(\mathrm{N}=3 \mathrm{I})\end{array}$}} & \multirow{2}{*}{\multicolumn{3}{|c|}{$\begin{array}{l}\text { Chronic } \\
\text { Psychotics } \\
(N=23)\end{array}$}} & \multirow{2}{*}{\multicolumn{3}{|c|}{$\begin{array}{c}\text { Acute } \\
\text { Psychotics } \\
(\mathrm{N}=2 I)\end{array}$}} & \multicolumn{3}{|c|}{$\underline{t}$} \\
\hline & & & & & & & & & & \multirow{2}{*}{ 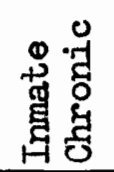 } & \multirow{2}{*}{ 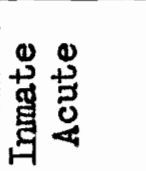 } & \multirow{2}{*}{ 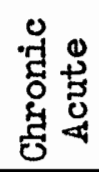 } \\
\hline & $\overline{\mathrm{D}}$ & $S \bar{D}$ & $\underline{t}$ & $\overline{\mathrm{D}}$ & $S \bar{D}$ & $\underline{t}$ & $\overline{\mathrm{D}}$ & $S \bar{D}$ & $\underline{t}$ & & & \\
\hline \multicolumn{8}{|c|}{ 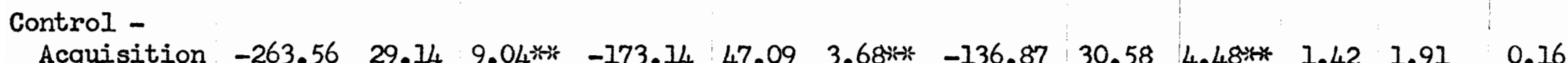 } & 30.58 & & & & \\
\hline $\begin{array}{r}\text { Control - } \\
\text { Extinction } \\
11-13\end{array}$ & -210.32 & 31.25 & $6.73 \div-4$ & -97.22 & 46.38 & $2.11 *$ & -26.87 & 21.80 & 1.23 & 0.91 & $2.47 \times 2$ & 1.18 \\
\hline $\begin{array}{r}\text { Acquisition } \\
\text { Extinction } \\
1-3\end{array}$ & -25.65 & 29.47 & 0.87 & -56.60 & 32.63 & 1.73 & 61.07 & 31.90 & 1.96 & 0.16 & 1.68 & 1.77 \\
\hline $\begin{array}{r}\text { Acquisition - } \\
\text { Extinction } \\
11-13\end{array}$ & 53.24 & 22.63 & $2.35 *$ & 75.92 & 41.13 & 1.85 & 110.00 & 20.18 & $5.45^{*-1}$ & 0.46 & 0.94 & 1.77 \\
\hline $\begin{array}{c}\text { Extinction } \\
1-3- \\
\text { Extinction } \\
11-13\end{array}$ & 78.74 & 28.48 & $2.73 \%$ & 132.52 & 42.44 & $3.12 \%$ & 48.93 & 28.52 & 1.72 & 0.44 & 0.91 & 1.20 \\
\hline
\end{tabular}

$* \mathrm{p}<.05$

$* * \mathrm{p}<.01$ 
in Study I and used response levels, between-level differences, and regression scores. None of the relationships studied was significant. This finding is comparable to that of Study I and is similar to the results reported by Campbell (1938) for knee jerk and eyeblink conditioning.

Effects of Severity of Psychosis

A correlational analysis similar to that reported in Study I was completed, using the data on the acute and chronic psychotics. None of the correlations between the conditioning measures and the objective tests and time in institution was significant. Thus, as in Study I, the hypothesized relationship between severity of psychosis and conditioning performance was not supported. It is possible that neither the objective performance test results nor time in institution are reliable measures of severity of psychotic illness. The present data, therefore, may not provide adequate information with which to assess the hypothesized association.

\section{Cross Validation}

While both studies employed comparable conditioning methods, differences between them in apparatus (see Procedure, Study II) did not permit the data to be pooled. It was nevertheless considered important to make some assessment of the comparability of the results of the two studies. Therefore, an analysis, using $t$ ratios, was made of the differences between the chronic psychotics of study $I$ and the chronic psychotics of Study II. The $\underline{S}$ s in these two groups were similar, aII having met the same selection criteria, and it was assumed that the effect of the modifications introduced in Study II would be to enhance inter-group differences rather than to reduce them. 
The results of this analysis indicated that both groups were of similar age, education and intelligence and that they had been hospitalized for equal periods of time. The two groups were also comparable with respect to anxiety level (MAS) and performance on the four objective tests ( $3 C, L P, V F, T A P)$.

The conditioning performance of the two groups was markedly similar, minor differences occurring only on GSR and salivation procedures. The chronics of Study I evidenced a higher CR level during the first $10 \mathrm{GSR}$ extinction trials than the chronics of Study II $(\underline{t}=2.26, p<.05)$ but had equivalent acquisition and extinction rates. The Study I chronics showed an immediate response decrement following withdrawal of reinforcement during salivation conditioning while the Study II chronics did not. Both groups of chronics showed similar acquisition rates and both evidenced final salivation extinction levels that were significantly higher than their control levels.

The verbal conditioning performance of the two groups was comparable in that neither group demonstrated significant conditioning effects.

The results of this cross validation study indicate that the performance and conditioning measures of Study I were comparable to those of Study II. Summary of Results

Significant conditioning effects under GSR and salivation procedures were obtained with the inmates, the acutes and the chronic psychotics. Only the acute psychotic group, however, demonstrated significant acquisition of the verbal response and in this regard were similar to the normals of Study $I$. 
Analysis of the GSR and salivation acquisition curves did not reveal any significant inter-group differences. The salivation extinction data, however, indicated that the acutes tended to return to response levels held prior to conditioning while the inmates and the chronics tended to perseverate acquisition effects. In this respect the similarity between the acutes of Study II and the normals of Study I may again be noted.

Using the objective test scores of the acute and chronic psychotics and the time in institution for the chronics an attempt was made to evaluate the effects of severity of illness upon conditioning rates. As in Study $I$, none of the relationships was found to be significant.

The main finding from this study, therefore, was that while the objective performance tests differentiated significantly between psychotic and non-psychotic Ss, the conditioning measures indicated important differences between institutionalized and non-institutionalized $\underline{\text { Ss. }}$ 


\section{DISCUSSION}

The results of the present research failed to confirm either the main hypothesis that the acquisition and/or extinction performance of psychotic Ss differs from that of non-psychotics or the related prediction that severity of psychosis correlates with conditioning rates. The data clearly indicated, however, that prolonged institutionalization had significant effects upon behaviour, regardless of whether the $\underline{S}$ was psychotic or non-psychotic.

In order to indicate the validity of this finding the data will be discussed as follows: firstly, with regard to the adequacy of the psychotic - non-psychotic classification; secondly, with reference to the properties of the stimuli used; thirdly, with respect to the hypotheses concerning the conditioning performance of psychotic Ss; and, finally, institutionalization will be discussed in terms of its effects upon reinforcer efficacy together with suggestions as to how these effects might be further studied. Psychotic - Non-psychotic Dimension

The failure to support the main hypothesis raises a question as to the validity of the psychotic - non-psychotic groupings employed in this research. Of central concern is the position of the inmate group, for it was the conditioning performance of this group which enabled the main hypothesis to be rejected and led to the establishment of the major finding regarding the effects of institutionalization. Indeed, the interpretation of the data along these lines is dependent upon the assumption that the inmate group was non-psychotic.

There can be little doubt that the chronic patients were correctly 
classified as being psychotic. The designation of the acute group also as psychotic is possibly more tenuous. However, with these $\underline{S}$, as with the normal and inmate groups, the weight of evidence comes from the results of the objective performance tests. These indicated unequivoca.Ily that the acute and chronic patients were similar and that they both differed significantly from the non-psychotics (normals and inmates). This finding of a performance decrement associated with psychotic $\underline{S}$ s is in agreement with many previous studies (Eysenck, 1952b; Huston and Shakow, 1946; King, 1954; Rodnick and Garmezy, 1957) and is further strengthened by the findings of the cross validation which revealed that the results of the objective performance tests of the two chronic groups were similar. The objective test data suggest that the acutes were correctly grouped as psychotic and that the normals and inmate $\underline{S} s$ were correctly grouped as non-psychotic. The freedom from psychosis in the latter two groups was further assumed in that the history of each of these Ss showed no evidence of previous mental iliness. It might be noted in this regard that psychiatric services were available to all inmate $\underline{S} s$ through medical or self referral.

Thus the objective test results and the psychiatric differentiation support the assumption that the groups were adequately selected in order to test the hypothesized difference between the conditioning performance of psychotics and non-psychotics.

Stimulus Properties

Before the differences in conditioning performance between groups can be examined it is necessary to establish that all groups were able to discriminate the stimuli employed. It will be recalled that attempts 
were made to provide phenomenological equivalence of stimuli across groups. The fact that the GSR and salivation acquisition performance of all groups was significant suggests that the groups were able to discriminate the conditioning stimuli employed. It was likewise apparent from the significant acquisition curves obtained under each conditioning task that the reinforcers selected were appropriate. The fact that no significant acquisition differences were found between groups on GSR, verbal or salivation conditioning suggests also that the properties associated with the reinforcers were consistent across groups. ${ }^{8}$ Thus it would seem reasonable to assume that differences in conditioning performance between groups could be attributed to $\underline{\mathbf{S}}$ characteristics rather than to stimulus properties. Conditioning in Psychotics.

It was hypothesised that the conditioning performance of psychotics differs from that of non-psychotics. In Study I, which employed normals and chronic psychotics, the hypothesis was supported in that the chronics failed to acquire the conditioned verbal responses and showed perseveration effects during salivation extinction. However, there were differences between these two population samples other than psychotic illness and alternative interpretations in terms of chronicity and

8 It is of interest to note the qualities of the reinforcements used: with GSR it was shock (assumed to have negative qualities); with verbal it was "Good" (generally held to have socially rewarding or positive qualities); and with salivation it was a sucker (thought to possess positive qualities). It has often been suggested (Cameron, 1947; Fenichel, 1945; Fromm-Reichmann, 1950) that psychotics perform differentially under reward-punishment conditions. The present data suggest that if the reinforcer is available to the psychotic $\underline{S}$ then his behaviour will be similar to that of the non-psychotic, regardless of whether the reinforcer is positive or negative. 
institutionalization were possible. It was principally to provide control over these factors that Study II was conducted. The results of this second study indicated that the conditioning performance of the chronics and the inmates was similar and that their conditioning performance differed from that of the acute psychotics. This finding suggested that differences in conditioning performance were not due to psychoticism.

The partial cross validation study showed that the conditioning performance of the chronics of Study I was comparable to that of the chronics of Study II. It is, therefore, possible to arrive at the following generalizations: I) all groups evidenced similar GSR conditioning effects; 2) significant verbal acquisition was obtained only with the normals and the acute psychotics; and 3) although all groups evidenced similar and significant acquisition, the final extinction levels of the normals and acute psychotics were the same as their control levels of salivation, whereas the terminal levels of the chronic psychotics and inmates were significantly higher than their own control levels.

Thus the conditioning performance of the chronics and inmates was similar and the conditioning performance of the normals and acute psychotics was similar. The concordance between the conditioning results of the institutionalized groups and between those of the noninstitutionalized groups suggests that the group differences in conditioning were related to factors of institutionalization.

The significance of this interpretation is increased when the two secondary hypotheses are considered. The hypothesis that the condition- 
ing performance of acute psychotics differs from that of chronic psychotics was supported by the data of Study II. It would appear, however, that the difference between these two groups was due to the fact that the chronics were institutionalized. 9

It is of interest to examine the failure in the present research to demonstrate a relationship between severity of illness and conditioning rates. Previous investigators (Astrup, 1957; Iindsley, 1956b; Mednick and Iindsley, 1958) have reported linear relationships between severity and conditioning rates, the severely ill patients conditioning more slowly than the less incapacitated $\underline{S} s$. In the present research the objective performance test results, because they were found to be independent of institutionalization, were taken as measures of severity. Previous research, however, had assessed severity through ratings of ward behaviour and by pooled ratings made by psychiatrists. It is possible that these measures, rather than assessing severity of illness, indicated instead the effects of institutionalization. If this assumption is correct, then the significant relationships reported between these measures and conditioning may reflect the communality of this factor rather than the effects of severity of illness. Institutionalization

It is generally accepted that restrictions are imposed by mental hospitals (Belknap, 1956; Clausen, 1959; Greenblatt, York and Brown,

9 It may of course be argued that the differences in conditioning performance between groups occurred because of differences in drive strength. The most direct evidence bearing upon this possibility was obtained from GSR log conductance measures, salivation secretion and the results of the MAS. An examination of these measures suggested that drive level was relatively homogeneous over all groups. 
1955; Jones, 1953) and by prisons (Clinard, 1959; Sutherland and Cressey, 1955; Train, 1947). In this respect the comments of Goffman (1958) and Wayne (1961) concerning mental patients and of Powelson and Bendix (1955) regarding prison inmates are of importance. Goffman (1958) has pointed out that mental hospitals commonly impose sanctions against many aspects of behaviour which are not subject to control outside the hospital, while at the same time tolerating many forms of behaviour which would be censured outside. Wayne (1961) has suggested that very often the praise given to mental patients following some activity is indulgent or inappropriate. In drawing a parallel between mental hospital and prison environments, Powelson and Bendix (1955) have emphasised that status differences between inmates and guards lead to interactions between them that are qualitatively negative and different from interactions which occur outside the prison. Thus it would seem reasonable to suppose that the reinforcement histories of Ss having prolonged institutionalization differ from those of noninstitutionalized Ss. ${ }^{10}$

This assumption offers a parsimonious explanation of many behavioural differences that have been observed between institutionalized and non-institutionalized $\underline{S}$. If a $\underline{S}^{\prime} s$ prior experience with a reinforcer influences his reaction to it, then the present conditioning data might be interpreted as reflecting differences between groups in reinforcement history.

10 In this connection it is of interest to consider the failure of Hartman (1955) to demonstrate a difference between the verbal conditioning performance of hospitalized psychotics and attendants. This result may have occurred because the institutional environment of both groups was similar. 
The results of this research and those of Cohen and Cohen (1960) and LeventhaI (1959) indicate that "Good" is an ineffective reinforcer when used with hospitalized psychotics. The fact that in the present study "Good" was also ineffective in modifying the verbal behaviour of inmate $\underline{S}$ s implies that the reduction in reward efficiency cannot be explained by the presence of psychotic illness. An explanation in terms of psychotic illness would be difficult to defend, too, in view of the significant acquisition effects demonstrated with the acute psychotics.

The indication that the institutionalized groups appeared resistant to extinction on the salivation procedure suggests that the sucker was a more effective reinforcer with them than with the noninstitutionalized Ss. Two interpretations compatible with an assumed difference in reinforcement history between the groups are available to explain this finding. There is the possibility that the institutionalized Ss had undergone some form of deprivation, the results of which increased the efficacy of the sucker reinforcements. This argument would be in accord with deprivation studies (Butler, 1957; Gewirtz and Baer, 1958; Scott, Bexton, Heron and Doane, 1959) which have generally shown an enhancement of stimulus effects following isolation. A more probable explanation, of course, is offered by the work of Razran (1949) and Humphreys (1943) who have shown that attitudes are important determinants of conditioning results. Because salivation was the last procedure used it is possible that the attitudes of the groups may have differed and that attitudinal differences may have influenced the salivation results. The non-institutionalized Is may have been looking forward to the termination of the procedure and to their release from 
the testing situation. On the other hand, the institutionalized Ss may have desired the procedure to continue rather than be obliged to return to their hospital wards or to their prison cells. While this interpretation is plausible, no direct test was made of it.

Thus the differences between the institutionalized and noninstitutionalized groups under conditions of positive reinforcement (verbal and salivation) may have occurred because of factors related to institutional care. This interpretation is given further support by the similarity reported between institutionalized and non-institutionalized Ss by studies which have employed reinforcers which may be assurned to be independent of a $\underline{S}^{\prime}$ institutional history. It is probable that the common meaning of censure is reliably maintained in institutions. Leventhal (1959) has reported significant verbal response acquisition with hospitalized schizophrenics with the verbal reinforcement "Not so good" which could be said to possess the qualities of a mild censure. II Similar results have been reported (Krasner and UIImann, 1958; Salzinger and Pisoni, 1958, 1960; Ullmann, Krasner and Collins, 196I) with verbal reinforcers such as "Uhuh", "Mmm", and "I see". It would appear reasonable to assume that the experiential histories of most Ss would be homogeneous with respect to these interjections and that their reinforcing efficacies would be similar across groups.

The finding in the present research that the groups did not differ

11 It is noteworthy that this censure was inefficient with neurotics (Ieventhal, 1959). It might be speculated that experience of neurotics with verbal censure is often unrealistic or inappropriate and that therefore the reinforcing qualities of censure are extinguished. 
with respect to GSR response acquisition is also pertinent in this regard. This result, supported by the work of Howe (1958) and Paintal (195I), is not surprising as it may be assumed that the past experience of the groups with electric shock was similar.

The fact that the differences in conditioning performance consistently separated institutionalized Ss from non-institutionalized Ss, and the fact that these differences occurred under two different conditioning procedures (verbal and salivation), argue against interpretations based on learning abilities, response sets and the like. It would also be difficult to maintain such interpretations and yet explain the GSR data, which was similar across groups.

An interpretation in terms of differences in reinforcement history, on the other hand, does not appear to violate the data; is supported by previous studies which have demonstrated that efficacy can be modified (Butler, 1957; Capretta, 196I; Gewertz and Baer, 1958); provides a rational basis for considering the chronic psychotics and inmates, and the acute psychotics and normals, as two different population samples; and focuses attention upon efficacy of reinforcement. Suggestions for Future Research

From the results of the present investigation it is apparent that studies of the interaction effects between social reinforcers and $\underline{\mathbf{S}}$ variables are required. Specifically, future research might: 1) compare groups of individuals from a larger range of 'institutionalization'

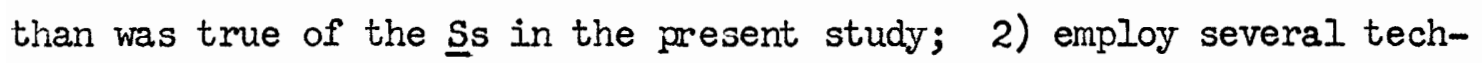
niques and several social reinforcers; and 3) employ experimenters of varied status, sex, and social class. 
SUMMARY

Theoretical attempts, notably by Pavlov, have been made under an assumption of constitutional deficit to explain behaviour pathology in conditioning terms. The evidence has established that psychotics can be conditioned but is equivocal concerning the conditioning ability of psychotics relative to normals.

The present study tested the hypothesis that the conditioning performance of psychotics differs from that of non-psychotics. Normals, penitentiary inmates, acute psychotics, and chronic psychotics were studied using GSR, verbal, and salivation conditioning procedures, and the performance of the chronic ㅇs was cross validated. The psychiatric differentiation of psychotic and non-psychotic was supported by the results of objective performance tests, on which the psychotics demonstrated a performance deficit.

The conditioning data failed to confirm the hypothesized effects of psychosis but indicated that institutionalization was an important factor influencing performance, irrespective of whether or not $\underline{S}$ was psychotic. The effects of institutionalization were interpreted in terms of reinforcement history. 
APPENDIX A

Verbal Conditioning

Stimulus verbs in Order of Presentation

\section{Operant}

1. saved

2. stepped

3. faced

4. Ied

5. guided

6. cut

7. spoke

8. gave

9. worked

10. opened

11. Iistened

12. proved

13. waited

14. sold

15. Iooked

16. called

17. rested

18. held

19. smiled

20. stood
Acquisition

21. came 41. rode 6I. closed

22. accepted

42. made

62. offered

23. admitted

43. covered

63. rais

24. used

44. felt

45. sang

64. grew

25. $\operatorname{ran}$

46. owned

65. rolled

26. talked

47. wanted

48. named

49. filied

50. crossed

66. lived

27. stopped

28. danced

29. waIked

30. got

51. cared

52. dropped

53. knew

54. hoped

55. demanded

56. fell

57. passed

58. helped

59. sat

60. took

67. became

68. met

69. went

70. sat

71. replied

72. asked

73. built

74. brought

75. serit

76. kept

77. gathered

78. spread

79. put

40. caused

80. laughed 
Extinction
81. dressed
101. cleared
82. returned
102. said
83. Iiked
103. carried
84. reached
104. attempted
85. saw
105. cooked
86. added
106. forgot
87. changed
107. agreed
83. rushed
108. counted
89. wished
109. circled
90. ordered
110. reported
91. picked
111. promised
92. painted
112. played
93. paid
113. acted
94. let
174. handed
95. shopped
115. answered
96. appeared
116. relieved
97. told
177. moved
93. refused
118. tried
99. finished
II9. shared
100. Ieft
120. began 


\begin{abstract}
APPENDIX B
Salivation Secretion With and Without Water Rinse
\end{abstract}

Method

Subjects

Ten chronic male psychotics, diagnosed schizophrenia, were tested. These $\underline{S}$ s had a mean age of 52.3 years $\left(S_{0} D_{0}=7.1\right)$ and had been in hospital for a mean period of 13.6 jears (S.D. = 4.2). AII Ss had been free from medication for at least three months prior to testing and none was receiving active treatment.

Procedure

The testing procedure followed the control testing earlier described under salivation. Auditory thresholds for a pure tone of 2000 cps were determined at the preferred ear for each $\underline{S}$ and testing was carried out with a sound level $35 \mathrm{db}$ above this threshold value. Two groups of five $\mathrm{Ss}$ were formed. Group I received 10 water rinse trials followed by 10 trials without water rinse, and Group II received 10 trials without rinse followed by 10 water rinse trials. The increase in weight of the cotton roll due to absorption of saliva was taken as the measure of salivation. Inter-trial intervals were 1 min。; trial length varied, the water rinse trials requiring $90 \mathrm{sec}$. and the no water rinse trials $60 \mathrm{sec}$. Thus, the testing procedure required approximately $45 \mathrm{~min}$.

\title{
Results
}

Both methods yielded reliable measures of salivation, productmoment correlations being .84 between the first five water and the last 
five water trials; .86 between the first five no water trials and the last five no water trials; and .84 between the 10 water trials and the 10 no water trials. There was, however, a significant difference between the levels of salivation recorded during the water trials and those without the mouth rinse. The mean salivation level in milligrams associated with the water rinse, 247 (S.D. = 93.77), was significantly lower $(p<.05)$ than the correlated mean of 346 (S.D. $=143.21$ ) associated with the no water rinse. Salivation during the water rinse trials was also less variant $(p<.05)$ than under the no water rinse procedure. The data indicated, too, that over the 45-min. test period salivation secretion rates were stable, there being no significant difference between the sums of the first five and last five test trials. Conclusion

Reliable salivation measurement may be obtained using Razran's cotton technique under either water rinse or no water conditions. Some advantage was seen in using the water technique in that less variance was associated with it. The results also indicated that the salivation response was maintained without significant change over the 45-min. test period. 


\section{APPENDIX C}

Information Regarding Inmate Subjects

\section{Offence}

breaking and entering with intent -24 possession of stolen goods -3

escape from custody - 6 robbery with violence - I

theft of motor vehicle $\quad-4$ manslaughter -1

false pretences and/or forgery - 3

(Some inmates had been convicted under more than one charge.)

Current Sentence

The 34 inmates were serving sentences having a median length of 3 years (range: $2-12$ years).

Recidivism

Of the 34 inmates, only 6 were first offenders. Previous records of the remaining 28 included:

suspended sentence

- 11 inmates; median 1 , range $1-5$

jail sentence

- 22 inmates; median 2, range 1 - 6

penitentiary sentence

- 19 inmates; median 1 , range 1 - 6 .

Alcohol

Alcohol was mentioned in the court records as being a contributing factor in eight cases.

Relation to Test Variables

Sub-groups, based on the above information, were formed and their test results were compared with those of the remaining $\underline{S}$. None of the differences analysed was significant. 


\section{APPENDIX D}

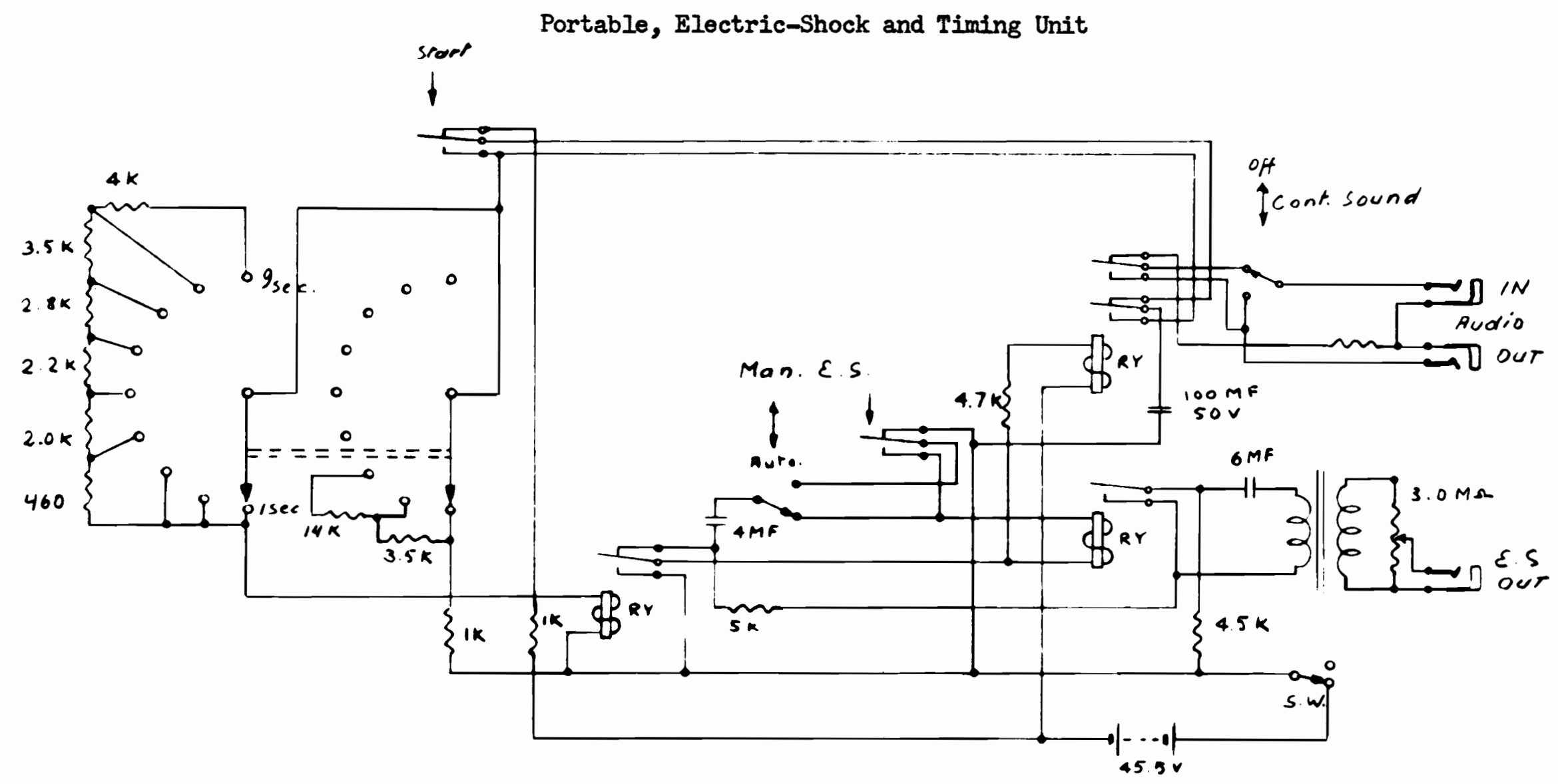

Designed by A. Rungas

Provincial Hospital

Lancaster, New Brunswick

February, 1960 


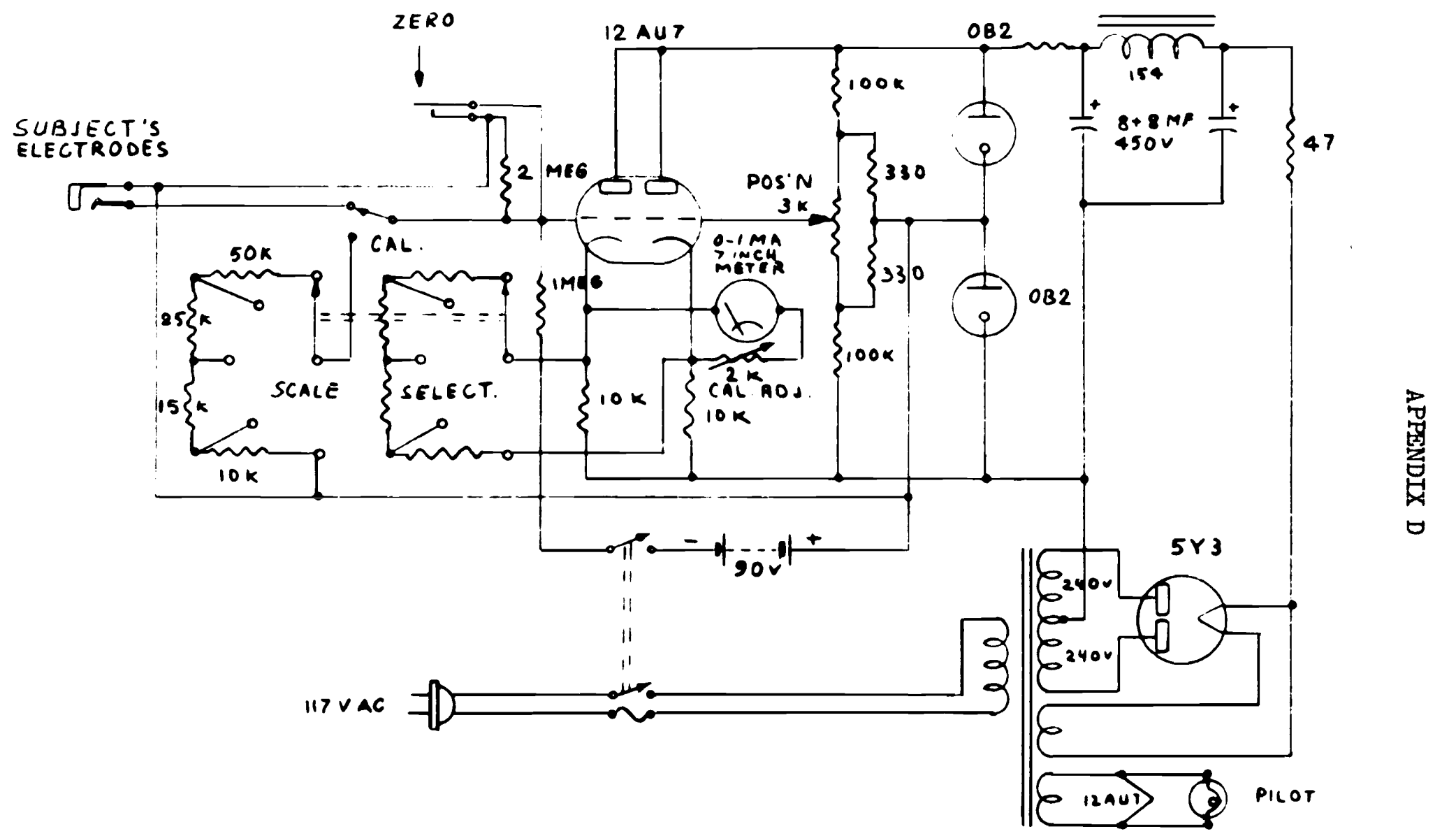

Portable, Direct-Reading Skin Resistance Meter

Designed by J.F. Davis, M.D. Allan Memorial Institute of Psychiatry

Montreal, Quebec

May, 1956 
REFERENCES

American Psychiatric Association, Committee on Nomenclature and Statistics. Diagnostic and statistical manual. Washington: Author, I952.

Amin, A.R. Notor performance of certain categories of mental patients. Percept. mot. Skills, 1960, 10, 39-42.

Ash, P. The reliability of psychiatric diagnoses. J. abnorm. soc. Psychol., 1949, 444, 272-276.

Astrup, C. Experimental investigations into the disturbances of higher nervous activity in deficit schizophrenics. Psychiat. Neurol. U. Med. Psychol., 1957, 2, 9-14.

Belknap, I. Human problems of a state mental hospital. New York: NicGraw Hili, 1956.

Bender, Lauretta, \& Schilder, P. Unconditioned reactions to pain in schizophrenia. Amer. J. Psychiat., 1930, 87, 365-384.

Benton, A.I., Jentsch, R.C., \& Wahler, H.J. Simple and choice reaction time in schizophrenia. AMA Arch. Neurol. Psychiat., 1959, 81, 373376.

Bindra, D. Experimental psychology and the problem of behaviour disorders. Canad. J. Psychol., 1959, 13, 135-150.

Bindra, D., Patterson, A.I., \& Strzelecki, Joanna. On the relation between anxiety and conditioning. Canad. J. Psychol., 1955, 2, 1-6.

Brogden, H.J. Sensory preconditioning of human subjects. J. exp. Psychol., 1947, 37, 527-539.

Brooke, Eileen, M. National statistics in the epidemiology of mental illness. J. ment. Sci., 1959, 105, 893-908.

Brown, C.C. Changes in avoidance conditioning following psychotherapeutic treatment. J. nerv. ment. Dis., 1957, 125, 487-489.

Buss, A.H., \& Gerjuoy, I.R. Verbal conditioning and anxiety. J. abnorm. soc. Psychol., 1958, 57, 249-250.

Butler, R.A. The effect of deprivation of visual incentives on visual exploration motivation in monkeys. J. comp. physiol. Psychol., 1957, 50, $177-179$.

Cameron, N. The psychology of behavior disorders. Boston: Houghton Mifflin, 1947. 
Campbell, A.A. The interrelations of two measures of conditioning in man. J. exp. Psychol., 1938, 22, 225-243.

Capretta, P.J. An experimental modification of food preference in chickens. J. comp. physiol. Psychol., 1961, 54, 238-242.

Clausen, J.A. The sociology of mental illness. In R.K. Merton, L. Broom, \& I.S. CottreIl (Eds.), Sociology today: problems and prospects. New York: Basic Books, 1959. Pp. 485-508.

Clinard, M. B. Criminological research. In R.K. Merton, L. Broom, \& I.S. Cottrell (Eds.), Sociology today: problems and prospects. New York: Basic Books, 1959. Pp. 509-536.

Cohen $B_{\bullet} D_{\bullet}$, Kalish, H.I., Thurstone, J.R., \& Cohen, E. Experimental manipulation of verbal behavior. J. exp. Psychol., 1954, 47, 106-110.

Cohen, E., \& Cohen, B.D. Verbal reinforcement in schizophrenia. I. abnorm. soc. Psychol., 1960, 60, 443-446.

Diethelm, 0. The fallacy of the concept: Psychosis. In P.H. Hoch \& J. Zubin (Eds.), Current problems in psychiatric diagnosis. New York: Greene \& Stratton, 1953. Pp. 24-32.

Doering, C.R. Reliability of observation of psychiatric and related characteristics. Amer. J. Orthopsychiat., 1934, 4, 249-257.

Dominion Bureau of Statistics, Health and Welfare Division. Mental statistics handbook (2nd ed.). Ottawa: Queen's Printer, 1954.

Doppelt, J.E. Estimating the full scale score on the Wechsler Adult Intelifigence Scale from scores on four subtests. J. consult. Psychol., 1956, 20, 63-66.

Edwards, A.S. A new apparatus for the measurement of bodily movement. J. exp. Psychol., 1939, 15, 125-126.

Eysenck, H.J. Cyclothymia - schizothymia as a dimension of personality. II. Experimental. J. Pers., 1952, 20, 345-384. (a)

Eysenck, H.J. The scientific study of personality. London: Routledge \& Kegan Paul, 1952. (b)

Eysenck, H.J. Dynamics of anxiety and hysteria. London: Routledge \& Kegan Paul, 1957.

Eysenck, H.J. Manual of the Maudsley Personality Inventory. London: Univer. London Press, 1959. 
Fenichel, 0. The psychoanalytical theory of neurosis. New York: Norton, 1945.

Fleck, S. Vigilance (Orienting Behavior), conditional reactions, and adjustment patterns in schizophrenic and compulsive patients. Ann. N.Y. Acad. Sci., 1953, 56, 342-377.

Foley, J.P. A note on the concepts of irritability and conditionability. J. gen. Psychol., 1943, 28, 143-145.

Franks, C.M. Effect of food, drink and tobacco deprivation on the conditioning of the eyeblink response. J. exp. Psychol., 1957, 53, 177-120.

Franks, C.M. Conditioning and abnormal behavior. In H.J. Eysenck (Ed.), Handbook of abnormal psychology: an experimental approach. New York: Basic Books, 1961. Pp. 457-487.

Fromm-Reichmann, Frieda. Principles of intensive psychotherapy. Chicago: Univer. Chicago Press, 1950.

Gantt, N.H. The conditioned reflex function as an aid in the study of the psychiatric patient. In P.H. Hoch and J. Zubin (Eds.), Relation of psychological tests to psychiatry. New York: Greene \& Stratton, 1952. Pp. 165-188.

Gewirtz, J.I., \& Baer, D.M. The effect of brief social deprivation on behaviors for a social reinforcer. J. abnorm. soc. Psychol., 1958, 56, 49-56.

Goffman, E. On the characteristics of total institutions. In Symposium on preventive and social psychiatry. Washington: Govt. Printing Office, 1958.

Grecker, R.A. Tactile reactions in catatonics studied by the method of associated reflexes. Unpublished thesis, St. Petersburg, 1911. Cited by Razran, G.H.S. Conditioned withdrawal responses with shock as the conditioning stimulus in adult human subjects. Psychol. Bull., $1934,31,111-143$.

Grcenblatt, M•, York, R.H., \& Brown, Esther I. From custodial to therapeutic patient care in mental hospitals. New York: Russell Sage Foundation, 1955 .

Guk, E.D. The conditioned reflex activity of schizophrenics. Sovetsk. Neuropatol., 1934, 74, E4. (Psychol. Abstr., 9:717)

Hartman, C.H. Verbal behavior of schizophrenic and normal subjects as a function of types of social reinforcement. Unpublished doctoral dissertation, State Univer. of Iowa, 1955. 
Hilgard, E.R., \& Marquis, D.G. Conditioning and learning. New York: Appleton, 1940.

Hollingshead, A.B., \& Redlich, F.C. Social stratification and psychiatric disorders. Amer. Sociol. Rev., 1953, 18, 163-169.

Howe, E.S. GSR conditioning in anxiety states, normals, and chronic functional schizophrenic subjects. J. abnorm. soc. Psychol., 1958, 56, 183-189.

HulI, C.I. Hypnosis and suggestibility. New York: Appleton Century, 1933.

Humphreys, L.G. Measures of strength of conditioned eyelid responses. J. gen. Psychol., 1943, 29, I0I-III.

Hunt, W.A., Wittson, C.I., \& Hunt, Edna B. A theoretical and practical analysis of the diagnostic process. In P.H. Hoch and J. Zubin (Eds.), Current problems in psychiatric diagnosis. New York: Greene \& Stratton, 1953. Pp. 53-65.

Huston, P.E., \& Shakow, D. Studies of motor function in schizophrenia: III, Steadiness. J. genet. Psychol., 1946, 34, 119-126.

Ivanov-Smolensky, A.G. Jber die bedingten Reflexe in der depressiven Phase dis manisch-depressiven Irreseins. Mschr. Psychiat. Neurol., 1925, 58, 376-388.

Jenkins, J.J., \& Iykken, D.T. Individual differences. Annu. Rev. Psychol., 1957, 으, 79-112.

Jones, M. The therapeutic community: a new treatment method in psychiatry. New York: Basic Books, 1953.

Kamin, L.J. Relations between discrimination, apparatus stress, and the Taylor scale. J. abnorm. soc. Psychol., 1955, 21, 595-599.

Kanfer, F.H. Effect of a warning signal preceding a noxious stimulus on verbal rate and heart rate. J. exp. Psychol., 1956, 56, 73-80.

Kiminel, H.D. Amount of conditioning and intensity of conditioned stimulus. J. exp. Psychol., 1959, 58, 283-287.

King, G.F., Armitage, S.G॰, \& Tilton, J.R. A therapeutic approach to schizophrenics of extreme pathology: An operant - interpersonal method. j. abnorm. soc. Psychol., 1960, 6I, 276-286.

King, G.F., Nerre1I, D.W., Lovinger, E., \& Denny, R.M. Operant motor behavior in acute schizophrenics. J. Pers., 1957, 2.5, 317-326.

King, H.E. Psychomotor aspects of mental disease. Cambridge: Harvard Univer. Press, 1954. 
Krasner, I. Studies of the conditioning of verbal behavior. Psvchol. BuI7., 1958, 25, 148-170. (a)

Krasner, I. A technique for investigating the relationship between the behavior cues of the examiner and the verbal behavior of the patient. J. consult. Psychol., 1958, 22, 364-366. (b)

Krasner, I., \& Ullmann, I. Variables in the verbal conditioning of schizophrenic subjects. Paper read at the Amer. Psychol. Ass., Washingt,on, 1958.

Iandkof, B.I. Unconditioned and conditioned vascular reflexes in schizophrenics. Trud. Tsentrol. Psckonevrol. Inst., 1938, 10, 37-63. (Psychol. Abstr., 12:5343)

Leventhal, A.M. The effects of diagnostic category and reinforcer on learning without awareness. J. abnorm. soc. Psychol., 1959, 29 , 162-166.

Ievin, S.M. The effects of awareness on verbal conditioning. J. exp. Psychol., 196I, 6I, 67-75.

Iindsley, $0 . R$. Operant conditioning methods applied to research in chronic schizophrenia. Fsychiat. Res. Rep., 1956, 5, 118-139. (a)

Iindsley, O.R. Reply to discussion. In G.N. Raines (Chairman), Discussion of paper presented by Ogden R. Iindsley. Psychiat. Res. Rep., 1956, 2, $140-153$. (b)

Lindsley, 0.R. Characteristics of the behavior of chronic psychotics as revealed by free-operant conditioning methods. Dis, nerv. Syst., $1960,21,3-15$.

Iindsley, O.R., \& Skinner, B.F. A method for the experinental analysis of the behavior of psychotic patients. Amer. Psychologist, 1954, 2 , 419-420. (Abstract)

Iittman, R.A. Conditioned generalization to the galvanic skin reaction to tones. J. exp. Psychol., 1949, 39, 868-882.

Iucero, R.J., \& Meyer, B.F. A behavior rating scale suitable for use in mental hospitals. J.clin. Psychcl., 1951, 1, 250-254.

Luria, A.R. Some problems of the higher nervous activity of normal and abnormal children. In A.R. Iuria (Ed.), Problems of the higher nervous activity of normal and abnormal children. Moscow: Acad. Pedagog. Sci., 1956.

Walmo, R.B., \& Crisp, I.R. A new reaction time apparatus and a new method of administering the reaction time test. Pub. Health Rep., $1945,60,947-958$. 
Mays, L.I. Studies of catatonia, V; investigation of the perseverational tendency. Psychiat. Quart., 1934, 으, 728-735.

Mednick, Martha T., \& Iindsley, O.R. Some clinical correlates of operant behavior. J. abnorm. soc. Psychol., 1958, 57, 13-16.

Mirolyubou, N.G., \& UgoI, N.B. The problem of the state of the process of excitation in schizophrenics. Sovrem. Psikhonevral., 1933, 6982. (Psychol. Abstr., 9:1260)

Mueller, H.F. An exploratory investigation of 'clinical-type' physiological indicators in the measurement of arousal. Unpub.lished thesis for diploma in psychiatry. McGill University, 1959.

Murphy, G. Personality: a biosocial approach to origin and structure. New York: Harper, 1947.

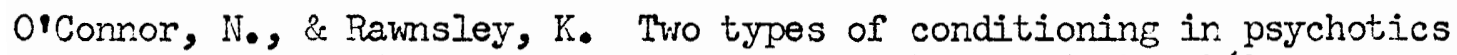
and normals. J. abnorm. soc. Psychol., 1959, 58, 157-161.

Osgood, C.E. Method and theory in experimental psychology. New York: Oxford Univer. Press, 1953.

Paintal, A.S. A comparison of the galvanic skin responses of normals and psychotics. J. exp. Psychol., 195I, 4I, 425-428.

Pavlov, I.P. Experimental psychology and psycho-pathology in animals. Paper read before intern. congress of Med., Madrid, 1903. In I.P. Pavlov, Iectures on conditioned reflexes. (Trans. W.H. Gantt) New York: Leveright, 1928. Pp. 47-60.

Peters, HaN., \& Murphree, 0.0. The conditioned reflex in the chronic schizophrenic. j. clin. Psychol., 1954, 10, 126-130.

Pfaffmar, C., \& Schlosberg, H. The conditioned knee jerk in psychotic and normal individuals. J. Psychol., 1936, I, 201-205.

Powelson, H., \& Bendix, R. Psychiatry in prison, In A.l. Rose (Ed.), viental health and mental disorder. New York: lorton, 1955. Pp. 459-48I.

Razran, G. A simple technique for controlling subjective attitudes in salivary conditioning of adult human subjects. Sci., 1939, 89, 160161.

Razran, G. Attitudinal determinants of conditioning and generalization of conditioning. J. exp. Psychol., 1949, 39, 820-829.

Richman, J. The effect of emotional tone of words upon the vocabulary responses of schizophrenics. J. gen. Psychol., 1957, 56, 95-119. 
Rodnick, E.H., \& Garmezy, N. An experimental approach to the study of motivation in schizophrenia. In M.R. Jones (Ed.), Nebraska symposium on motivation. Iincoln: Univer. Nebraska Press, 1957. Pp. 109-184.

Rosenbaum, G., Mackavey, W.R., \& Grisell, J.I. Effects of biological and social motivation on schizophrenic reaction time. J. abnorm. soc. Psychol., 1957, 54, 364-368.


J. gen. Psychol., 1959, 61, 65-94.

Salzinger, K॰, \& Pisoni, Stephanie. Reinforcement of affect responses of schizophrenics during the clinical interview. J. abnorm. soc. Psychol., 1958, 57, 84-90.

Salzinger, K., \& Pisoni, Stephanie. Reinforcement of verbal affect responses of normal subjects during the interview. J. abnorm. soc. Psychol., 1960, 60, 127-130.

Schnore, M.M. Individual patterns of physiological activity as a function of task differences and degree of arousal. $J_{\text {. exp. }}$ Psychol., 1959, 58, 117-128.

Scott, T.H., Bexton, W.H., Heron, W., \& Doane, B.K. Cognitive effects of perceptual isolation. Canad. J. Psychol., 1959, 13, 200-209.

Shipley, W.C. Studies of catatonia, VI: Further investigation of the perseverative tendency. Psychiat. Quart., 1934, \&, 736-744.

Siegel, S. Nonparametric statistics. New York: NicGraw-Hill, 1956.

Skinner, B.F. A new method for the experimental analysis of the behavior of psychotic patients. J. nerv. ment. Dis., 1954, 120, 403-406.

Skinner, B.F. What is psychotic behavior? In Theory and treatment of the psychoses: Some newer aspects. St. Louis: Washington Univer. Press, 1956. Pp. 77-99.

Skinner, B.F., Solomon, H.C., \& Iindsley, O.R. Annual Technical Report 3 to group Psychology Branch, Office of Naval Research. Report for the third year on new techniques of analysis of psychotic behavior. Sept. 1955-Nov. 1956.

Spence, K.W., \& Taylor, Janet A. The relation of conditioned response strength to anxiety in normal, neurotic and psychotic subjects. J. exp. Psychol., 1953, 45, 265-272.

Stennett, R.G. The relationship of alpha amplitude to level of palmar conductance. EEG. CIin. Neurophysiol., 1957, 2, 131-138. 
Stewart, M.A., Winolur, G., Stern, U., Guse, S., Pfeiffer, E., \& Hornug, F. Adaptation and conditioning of the GSR in psychiatric patients. J. ment. Sci., 1959, 105, 1102-1111.

Stolsky, B.A. Motivation and task complexity as factors in psychomotor responses of schizophrenics. J. Pers., 1957, 25, 327-343.

Sutherland, E.I., \& Cressey, D.R. Principles of criminology. New York: Iippincott, 1955.

Taffel, C. Anxiety and the conditioning of verbal behavior. J. abnorm. soc. Psychol., 1955, 51, 496-501.

Tatarenko, N.P. Disorders of the conditioned-reflex activity in patients with senile psychosis. Sovrem. Psikhonevral., 1934, 75-87. (Psychol. Abstr., 9:757)

Taylor, Janet A. A personality scale of manifest anxiety. J. abnorm. soc. Psychol., 1953, 48, 285-290.

Taylor, Janet A., \& Spence, K. . Conditioning level in the behavior disorders. J. abnorm. soc. Psychol., 1954, 49, 497-502.

Thorndike, E.I., \& Iorge, I. The teachers word book of 30,000 words. New York: Bureau of Publications, Teachers College, Columbia Univer., 1944.

Tizard, J., \& Venables, P.H. Reaction time responses by schizophrenic, mental defectives and normal adults. Amer. J. Psychiat., 1956, I12, $803-807$.

Train, G.J. Rapport in the penitentiary. In R.M. Iindner \& R.V. Siliger (Eds.), Handbook of correctional esychology. New York: Philosophical Iibrary, 1947. $\mathrm{Pp} .422-439$.

UIImann, I.P., Krasner, I॰, \& Collins, Beverly J. Hodification of behavior through verbal conditioning: Effects in group therapy. J. abnorm. soc. Psychol., 1961, 62, 128-132.

Vogel, liuriel D. The relation of personality factors to GSR conditioning of alcoholics: An exploratory study. Canad. J. Psychol., 1960, 14, $275-280$.

Wayne, G.J. Work therapy in the Soviet Union. Ment. Hosp., 1961, 12, $20-23$.

Willett, R. Cited by H.G. Jones, Symposium on Inhibition: IV. Individual differences in inhibitory potential. Brit. J. Psychol., 1960, 5I, 220-225.

Woodworth, R.S., \& Schlosberg, H. Experimental psychology. New York: Henry Holt, 2954 . 